\title{
Effect of In Situ Grown BNNTs and Preparation Temperature on Mechanical Behavior of SiC/SiC Minicomposites
}

\section{Shenwei Xu}

Central South University

\section{Huilong Pi}

Northwestern Polytechnical University

\section{Pengfei Wu}

Central South University

\section{Yuan Shi}

German Aerospace Center DLR Institute of Planetary Research: Deutsches Zentrum fur Luft- und Raumfahrt DLR Institut fur Planetenforschung

\section{Haitang Yang ( $\nabla$ hai.tang.ouyang@hotmail.com )}

Central South University

\section{Longbiao Li}

Nanjing University of Aeronautics and Astronautics

\section{Xiaozhong Huang}

Central South University

\section{Research Article}

Keywords: Ceramic matrix composites (CMCs), Boron nitr ide nanotubes (BNNTs) BNNTs), M ech anical behavior, Precurs or Infiltration and Pyrolysis PIP

Posted Date: March 8th, 2021

DOI: https://doi.org/10.21203/rs.3.rs-284157/v1

License: (c) (i) This work is licensed under a Creative Commons Attribution 4.0 International License. Read Full License 


\title{
Effect of In Situ Grown BNNTs and Preparation Temperature on Mechanical Behavior of SiC/SiC Minicomposites
}

\author{
Shenwei $\mathrm{Xu}^{a, b, c, \dagger}$, Huiling $\mathrm{Pi}^{d, \dagger}$, Pengfei $\mathrm{Wu}^{e}$, Yuan Shif, \\ Haitang Yang ${ }^{a, b, c, g *}$, Longbiao $\mathrm{Li}^{h}$ \\ ${ }^{a}$ Powder Metallurgy Research Institute, Central South University, Changsha, Hunan 410083, China \\ ${ }^{b}$ State Key Laboratory of Powder Metallurgy, Central South University, Changsha, Hunan 410083, China \\ ${ }^{c}$ Hunan Province Key Laboratory of New Specialty Fibers and Composite Material, Central South University, \\ Changsha, Hunan 410083, China \\ ${ }^{d}$ Science and Technology on Thermostructural Composite Materials Laboratory, Northwestern Polytechnical \\ University, Xican, Shanxi 710072, China \\ e School of Aeronautics and Astronautics, Central South University, Changsha, Hunan 410083, China \\ ${ }^{f}$ Institute of Structures and Design, German Aerospace Center Stuttgart, Pfaffenwaldring 38-40, 70569 Stuttgart, \\ Germany \\ ${ }^{g}$ State Key Laboratory of High Performance Complex Manufacturing, Central South University, Changsha, Hunan \\ 410083, China \\ ${ }^{h}$ College of Civil Aviation, Nanjing University of Aeronautics and Astronautics, No.29, Jiangjun Ave., Nanjing \\ 211106, PR China
}

$\dagger$ Shenwei Xu and Huiling Pi contributed equally to this work

* Corresponding author:

Email: hai.tang.ouyang@hotmail.com 


\begin{abstract}
In this paper, effect of in situ grown boron nitride nanotubes (BNNTs) and preparation temperature on mechanical behavior of PIP (Precursor Infiltration and Pyrolysis) $\mathrm{SiC} / \mathrm{SiC}$ minicomposites under monotonic and compliance tensile is investigated. In situ BNNTs are grown on the surface of SiC fibers using ball milling - annealing process. Composite elastic modulus, tensile strength, fracture strain, tangent modulus, and loading/unloading inverse tangent modulus (ITM) are obtained and adopted to characterize the mechanical properties of the composites. Microstructures of in situ grown BNNTs and tensile fracture surfaces are observed under scanning electronic microscopic (SEM). For SiC/SiC minicomposites with BNNTs, the elastic modulus, tensile strength, and fracture strain are all lower than those of $\mathrm{SiC} / \mathrm{SiC}$ minicomposites without BNNTs, mainly due to high preparation temperature and the oxidation of the PyC interphase during the annealing process. Tensile stress-strain curves of $\mathrm{SiC} / \mathrm{SiC}$ minicomposites with and without BNNTs are predicted using the developed micromechanical constitutive model. The predicted results agreed with experimental data. This work will provide guidance for predicting the service life of $\mathrm{SiC}_{\mathrm{f}} / \mathrm{SiC}$ composite materials and may enable these materials to become a backbone for thermal structure systems in aerospace applications.
\end{abstract}

Keywords: Ceramic-matrix composites (CMCs); Boron nitride nanotubes (BNNTs); Mechanical behavior; Precursor Infiltration and Pyrolysis (PIP). 


\section{Introduction}

Continuous silicon carbide fiber reinforced silicon carbide ceramic matrix composites ( $\mathrm{SiC} / \mathrm{SiC} \mathrm{CMCs}$ ) have the advantages of low density, high temperature resistance, oxidation resistance, high specific strength, and high specific modulus, and have become an important candidate material for the hot-section components of next generation high-performance aero-engine [[1]-[4]]. The introduction of fiber and the design of fiber/matrix interface can stimulate the energy consumption mechanism such as interfacial debonding and crack deflection and endow the material with non-brittle fracture characteristics [[5]]. However, on the one hand, the matrix between fibers, between fiber bundles and between layers is brittle ceramics and difficult to be strengthened and toughened by the energy consumption mechanism in micron scale; on the other hand, the crack initiation threshold in the matrix is low, and the crack propagation cannot be hindered, which ultimately limits the mechanical properties of the material. Therefore, as the weak region in the material, the micro region of matrix needs to be strengthened and toughened in a finer scale to improve its properties. Boron nitride nanotubes (BNNTs) have excellent mechanical, chemical and thermal stability. The oxidation resistance temperature is up to $900{ }^{\circ} \mathrm{C}$. The introduction of BNNTs into the material, as the second reinforcement in addition to the microfiber, can improve the mechanical properties of the matrix by strengthening and toughening the micro area matrix in the nano scale, and finally realize the optimization of the overall properties of the material [[6]-[8]].

Many researchers performed experimental and theoretical investigations on the mechanical behavior of ceramic or CMCs with BNNTs. Bansal et al. [[9], [10]] firstly introduced BNNTs into ceramic materials to prepare BNNTs reinforced barium calcium aluminosilicate (BACS) glass. Experimental results showed that the room temperature bending strength and fracture toughness of the glass increased by $90 \%$ and $35 \%$ respectively after adding $4 \mathrm{wt} \%$ BNNTs, which verified the strengthening and toughening effect of BNNTs. Based on the experimental results, Bansal et al [[9], [10]] 
analyzed that the debonding and pull-out mechanism of BNNTs is similar to the strengthening and toughening mechanism of fiber or whisker, which may be the reason for the improvement of glass strength and toughness. Huang et al. [[11]] studied the BNNTs reinforced $\mathrm{Al}_{2} \mathrm{O}_{3}$ and $\mathrm{Si}_{3} \mathrm{~N}_{4}$ composites. The results showed that the Vickers hardness of $\mathrm{Al}_{2} \mathrm{O}_{3}$ increased from 17.3 to $19.1 \mathrm{GPa}$ when the content of BNNTs increased to $0.5 \mathrm{wt} \%$, and the hardness decreased to $14.5 \mathrm{GPa}$ when the content of BNNTs increased to $2.5 \mathrm{wt} \%$. The Young's modulus decreased with the content of BNNTs increased. The Vickers hardness and Young's modulus of $\mathrm{Si}_{3} \mathrm{~N}_{4}$ decreased with the increase of BNNTs content. However, the high temperature plastic deformation ability of the two ceramics was greatly improved after the introduction of BNNTs. Hurst [[12]] verified the feasibility of in-situ growth of BNNTs in SiC fiber bundles and SiC fiber preforms and confirmed the strengthening effect of BNNTs on the mechanical properties of $\mathrm{SiC} / \mathrm{SiC}$ composites. Using $\mathrm{B}$ powder, $\mathrm{B}_{2} \mathrm{O}_{3}$ powder, $\mathrm{N}_{2}$ and $\mathrm{NH}_{3}$ as raw materials, BNNTs were successfully grown on the surface and inside of fiber bundles and fiber preforms by CVD method. The introduction of BNNTs into the fibers of $\mathrm{SiC} / \mathrm{SiC}$ composites can reduce the number of crack initiation in the matrix and eventually improve the tensile strength. The modeling of mechanical properties is a prerequisite for the further development and application of PIP SiC/SiC composite. $\mathrm{Li}$ et al. [[13], [14]] developed a micromechanical constitutive model to predict the monotonic and cyclic tensile behavior of unidirectional, cross-ply, and 2D plain-woven CMCs. Li [[15]] analyzed the effect of stochastic loading on tensile behavior of different CMCs. Li [[16]] developed a time-dependent tensile constitutive model to predict the tensile stress-strain curves considering time-dependent interface damage and fibers fracture. Up until now, it has not been studied the effects of the preparation temperature of BNNTs on the mechanical properties of $\mathrm{SiC} / \mathrm{SiC}$ composites.

The objective of this paper is to fabricate the $\mathrm{SiC} / \mathrm{SiC}$ minicomposites with and without BNNTs. The mechanical behavior of SiC/SiC with, without BNNTs and the preparation temperature is investigated under monotonic and compliance tensile loading. Microstructures of BNNTs are observed under the scanning electronic microscopic (SEM), and the tensile damage and fracture process are analyzed and related with micro 
damage mechanisms insider of composites. A micromechanical constitutive relationship is developed to predict the nonlinear mechanical behavior of $\mathrm{SiC} / \mathrm{SiC}$ minicomposites. The composite's tangent modulus and unloading and reloading inverse tangent modulus (ITM) are calculated and analyzed to characterize the tensile damage behavior of the composites. The composite's tensile strength, fracture strain, tangent modulus, loading/unloading ITMs are compared between $\mathrm{SiC} / \mathrm{SiC}$ minicomposites with and without BNNTs.

\section{Materials and experimental procedures}

To develop the in situ BNNTs on the surface of SiC fiber, mixed powder of $\mathrm{B}$ powder, $\mathrm{MgO}$ powder and $\mathrm{Fe}_{2} \mathrm{O}_{3}$ powder with mass ratio of 2:1:1 was prepared. The precursor powder with uniform dispersion and smaller particle size was obtained by planetary ball mill milling for $100 \mathrm{~h}$, and then spread evenly to the porcelain boat. The $\mathrm{SiC}$ fiber bundles with a PyC interface layer were wound on the porcelain boat covered with a layer of precursor powder, and then annealed in a tubular furnace at approximately $1300{ }^{\circ} \mathrm{C}$, as shown in Fig. 1. In the early stage, Ar was used as the protective atmosphere. When the temperature was raised to approximately $1300{ }^{\circ} \mathrm{C}$, $\mathrm{NH}_{3}$ was used as the nitrogen source, and the annealing time was $120 \mathrm{~min}$. After annealing, it is cooled down to room temperature. For comparison, the same SiC fiber bundles were wound on the porcelain boat without precursor powder and annealed accordingly. After the sample was taken out, it was found that the surface of fiber bundles with precursor powder in the porcelain boat became white, while the surface of fiber bundles without precursor powder had no obvious change. Then, the matrix of the two treated fiber bundles was densified by PIP process. Polycarbosilane (PCS) was used as raw material, and the weight gain was less than $1 \%$ after three PIP processes. Table 1 listed the general properties of $\mathrm{SiC} / \mathrm{SiC}$ mincomposites with and without BNNTs.

Table 1. General properties of $\mathrm{SiC} / \mathrm{SiC}$ minicomposites

\begin{tabular}{ccccc}
\hline Type of sample & Porosity & Density & Fiber volume content & Fiber orientation \\
\hline $\mathrm{SiC} / \mathrm{PyC} / \mathrm{SiC}$ & $\leq 10 \%$ & $\leq 2.5 \mathrm{~g} / \mathrm{cm}^{3}$ & $45 \%$ & Unidirectional \\
\hline
\end{tabular}




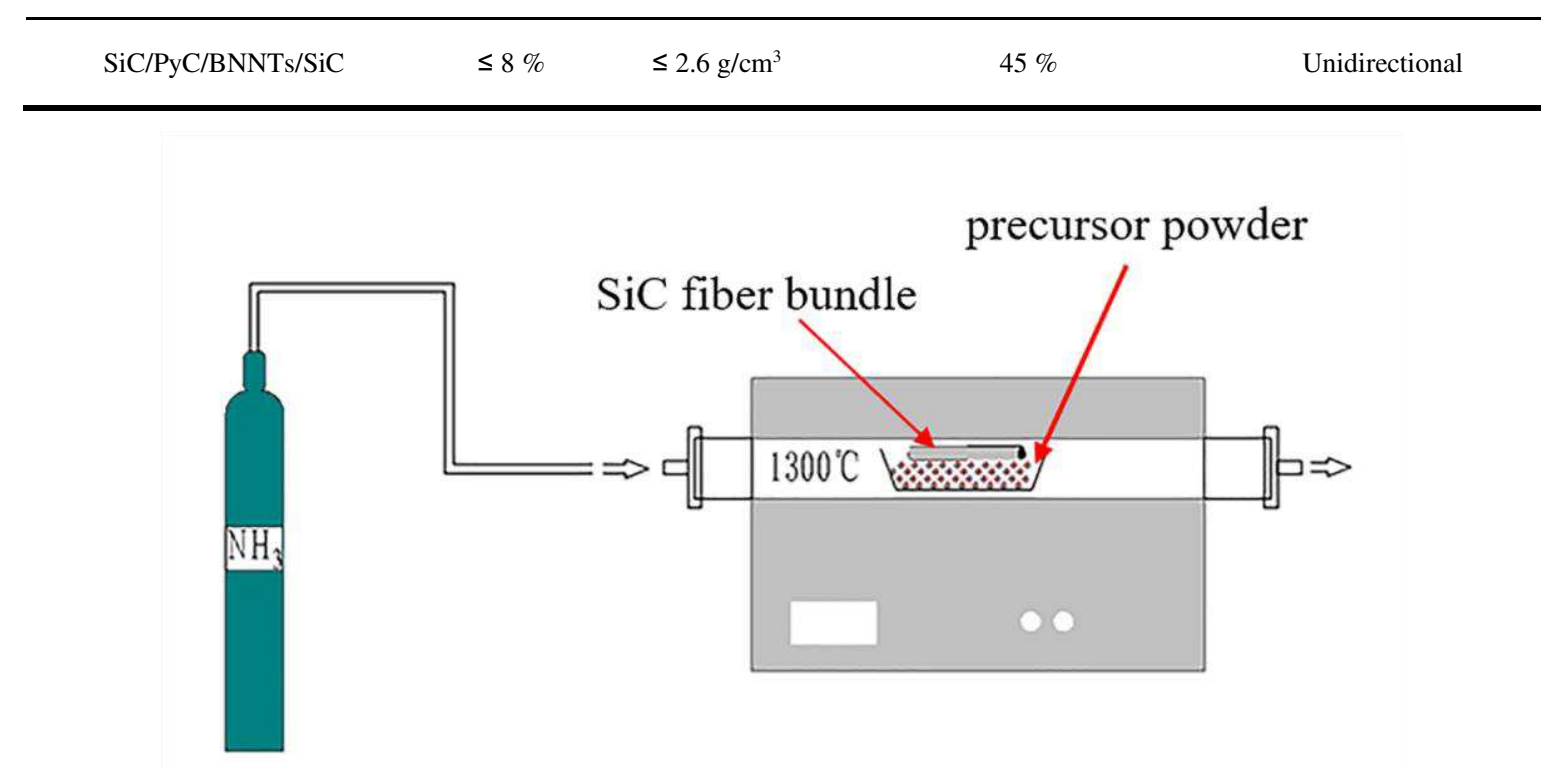

Fig. 1. Schematic of fabrication of BNNTs using ball milling - annealing method.

The fabricated $\mathrm{SiC} / \mathrm{SiC}$ minicomposites with and without BNNTs were cut into the specimens with dimensions of $50 \mathrm{~mm}$ in total length, as shown in Fig. 2. Monotonic and cyclic compliance tensile tests were conducted on MTS Insight electrical tensile testing machine (MTS Systems Corp., Minneapolis, MN, USA), as shown in Fig. 3. Tensile tests were conducted under displacement control with the loading rate of $0.01 \mathrm{~mm} / \mathrm{min}$.

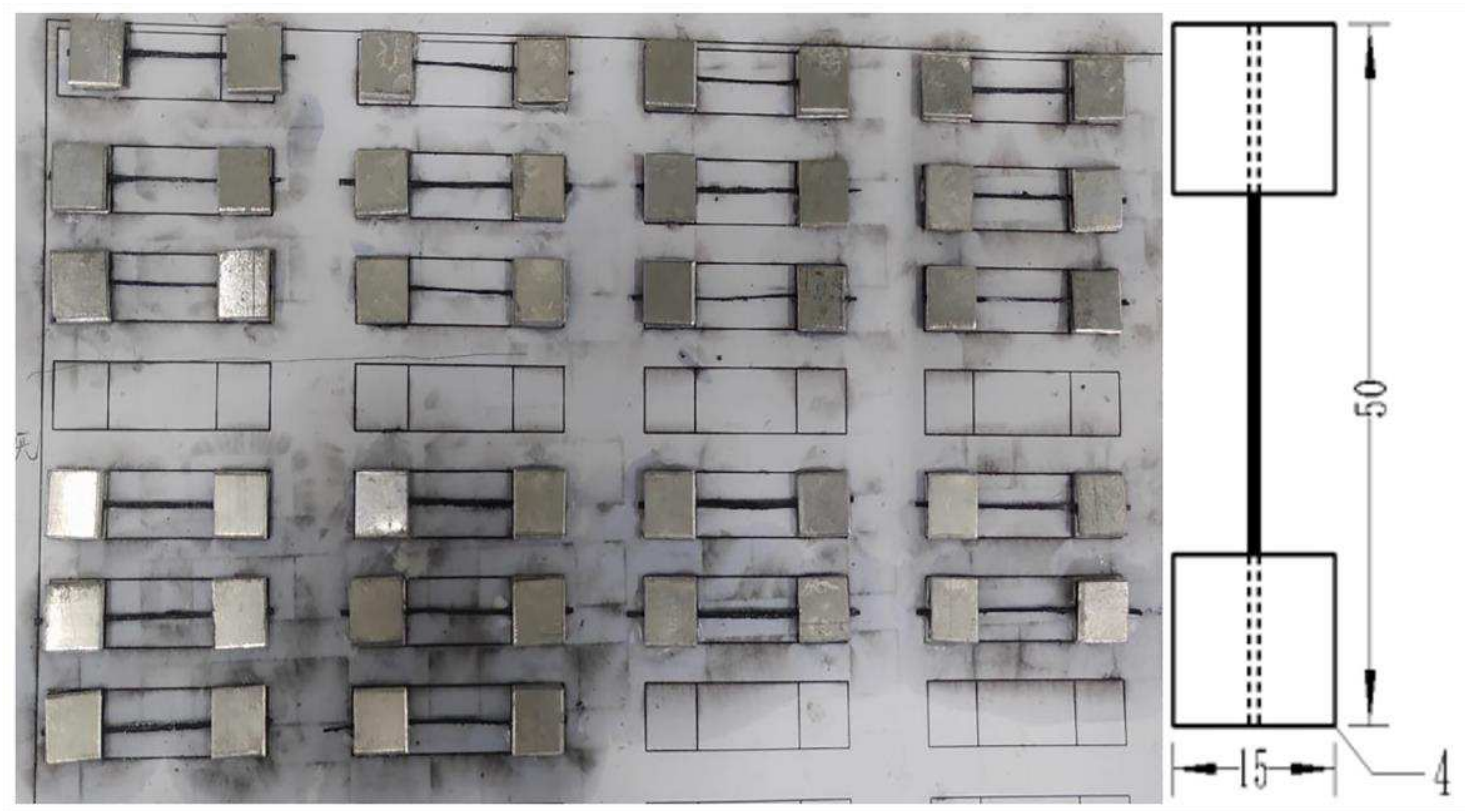

Fig. 2. Schematic of tensile specimens of $\mathrm{SiC} / \mathrm{SiC}$ composites with and without BNNTs 


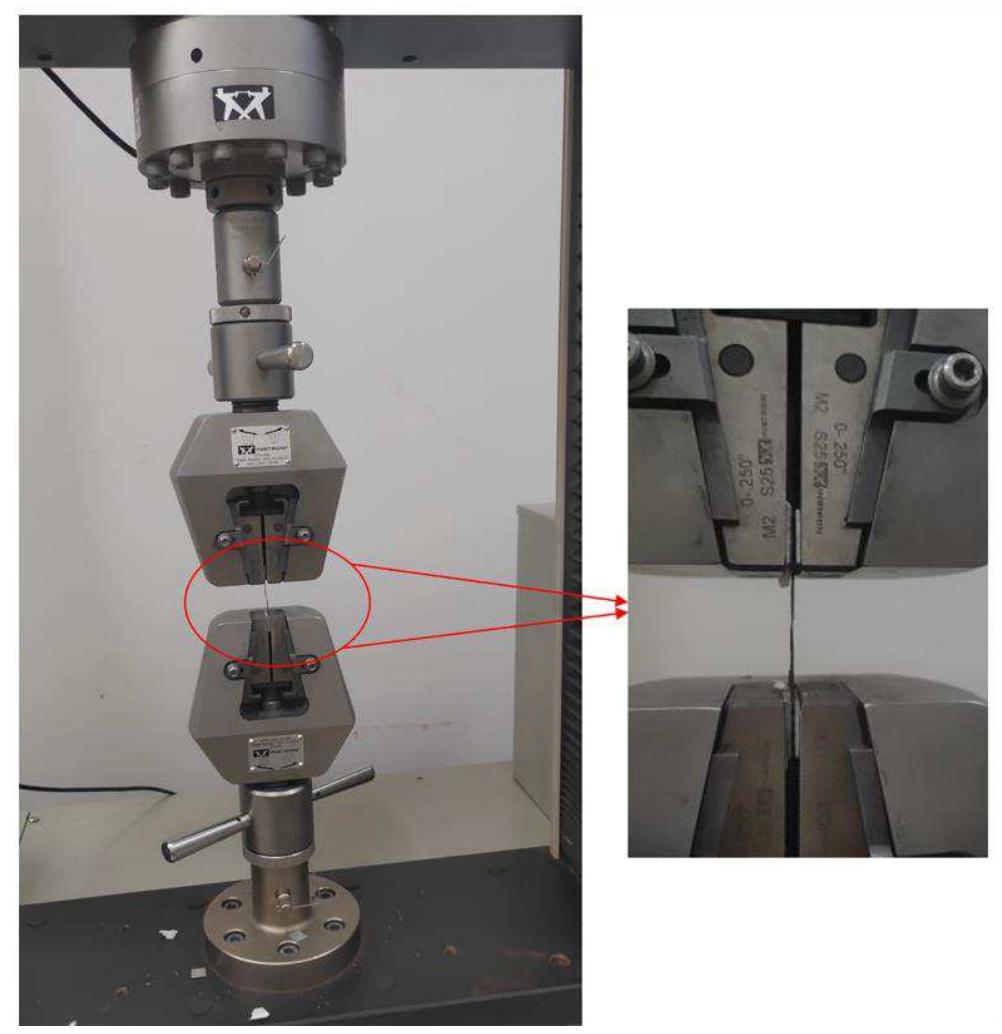

Fig. 3. Schematic of testing machine and tensile specimen.

\section{Micromechanical constitutive model}

Nonlinear behavior of mini-CMCs under tensile loading is mainly attributed to multiple micro damage mechanisms in the fiber, the matrix, and the interface between the fiber and the matrix [[16]-[18]]. Tensile nonlinear behavior of mini-CMCs can be divided into three main stages based on the internal damage state, including:

- Stage I, the linear-elastic region.

- Stage II, the nonlinear region due to micro damages.

- Stage III, the secondary linear and final fracture region due to gradual fiber fracture.

In this section, a micromechanical constitutive relationship of the three stages mentioned above is developed and related with micro damage state inside of mini-CMCs.

\subsection{Stage}

In Stage I, there is no damages occurred in mini-CMCs, and the linear-elastic stress-strain relationship is, 


$$
\varepsilon_{\mathrm{c}}=\frac{\sigma}{E_{\mathrm{c}}}
$$

where $\sigma$ is the applied stress, and $E_{\mathrm{c}}$ is the composite's elastic modulus.

\subsection{Stage II}

When multiple micro damage mechanisms occur in the mini-CMCs, the nonlinear stress-strain relationship is,

$$
\varepsilon_{\mathrm{c}}(\sigma)=\left\{\begin{array}{l}
\frac{\sigma}{V_{\mathrm{f}} E_{\mathrm{f}}} \eta-\frac{\tau_{\mathrm{i}}}{E_{\mathrm{f}}} \frac{l_{\mathrm{d}}}{r_{\mathrm{f}}} \eta+\frac{\sigma_{\mathrm{fo}}}{E_{\mathrm{f}}}(1-\eta)-\frac{1}{\rho E_{\mathrm{f}}} \frac{2 r_{\mathrm{f}}}{l_{\mathrm{c}}}\left(\frac{V_{\mathrm{m}}}{V_{\mathrm{f}}} \sigma_{\mathrm{mo}}-2 \frac{l_{\mathrm{d}}}{r_{\mathrm{f}}} \tau_{\mathrm{i}}\right) \\
\quad \times\left[\exp \left(-\frac{\rho}{2} \frac{l_{\mathrm{c}}}{r_{\mathrm{f}}}(1-\eta)\right)-1\right]-\left(\alpha_{\mathrm{c}}-\alpha_{\mathrm{f}}\right) \Delta \mathrm{T}, \eta<1 \\
\frac{\sigma}{V_{\mathrm{f}} E_{\mathrm{f}}}-\frac{\tau_{\mathrm{i}}}{2 E_{\mathrm{f}}} \frac{l_{\mathrm{c}}}{r_{\mathrm{f}}}-\left(\alpha_{\mathrm{c}}-\alpha_{\mathrm{f}}\right) \Delta \mathrm{T}, \eta=1
\end{array}\right.
$$

where $V_{\mathrm{f}}$ and $V_{\mathrm{m}}$ are the volume of the fiber and the matrix, $E_{\mathrm{f}}$ is the modulus of the fiber, $\tau_{\mathrm{i}}$ is the shear stress at the interface, $r_{\mathrm{f}}$ is the fiber radius, $l_{\mathrm{d}}$ and $l_{\mathrm{c}}$ are the length of the debonding and the space between the cracking in the matrix, $\alpha_{\mathrm{f}}$ and $\alpha_{\mathrm{c}}$ are the axial thermal expansional coefficient of the fiber and the composite, and $\Delta \mathrm{T}$ is the temperature difference between testing and fabricated temperature. Curtin [[19]] developed a stochastic model to analysis matrix stochastic cracking inside of CMCs, and the relationship between matrix crack spacing and applied stress can be determined by Eq. (3). Gao et al. [[20]] developed a fracture mechanical approach to determine the interface debonding length when matrix crack propagates to the interface, and the relationship between the interface debonding length and the applied stress can be determined by Eq. (4).

$$
\begin{gathered}
l_{\mathrm{c}}=l_{\mathrm{sat}}\left\{1-\exp \left[-\left(\frac{\sigma_{\mathrm{m}}}{\sigma_{\mathrm{R}}}\right)^{m}\right]\right\}^{-1} \\
l_{\mathrm{d}}=\frac{r_{\mathrm{f}}}{2}\left(\frac{V_{\mathrm{m}} E_{\mathrm{m}} \sigma}{V_{\mathrm{f}} E_{\mathrm{c}} \tau_{\mathrm{i}}}-\frac{1}{\rho}\right)-\sqrt{\left(\frac{r_{\mathrm{f}}}{2 \rho}\right)^{2}+\frac{r_{\mathrm{f}} V_{\mathrm{m}} E_{\mathrm{m}} E_{\mathrm{f}}}{E_{\mathrm{c}} \tau_{\mathrm{i}}^{2}} \zeta_{\mathrm{d}}}
\end{gathered}
$$

where $l_{\text {sat }}$ is the saturation length of matrix cracking, $\sigma_{\mathrm{m}}$ is the stress carried by the matrix, $\sigma_{\mathrm{R}}$ is the characteristic stress for cracking in the matrix, and $\zeta_{\mathrm{d}}$ is the debonding energy at the interface.

During damage Stage II, a new damage parameter of interface debonding ratio is, 


$$
\eta=2 \frac{l_{\mathrm{d}}}{l_{\mathrm{c}}}
$$

\subsection{Stage III}

Upon approaching saturation of the cracking in the matrix, fibers gradually fracture inside of the composite. Considering fiber's failure, the stress-strain relationship at the Stage III is,

$$
\varepsilon_{\mathrm{c}}(\sigma)=\left\{\begin{array}{l}
\frac{\Phi}{E_{\mathrm{f}}} \eta-\frac{\tau_{\mathrm{i}}}{E_{\mathrm{f}}} \frac{l_{\mathrm{d}}}{r_{\mathrm{f}}} \eta+\frac{\sigma_{\mathrm{fo}}}{E_{\mathrm{f}}}(1-\eta)-\frac{1}{\rho E_{\mathrm{f}}} \frac{2 r_{\mathrm{f}}}{l_{\mathrm{c}}}\left(\Phi-\sigma_{\mathrm{fo}}-2 \frac{l_{\mathrm{d}}}{r_{\mathrm{f}}} \tau_{\mathrm{i}}\right) \\
\quad \times\left[\exp \left(-\frac{\rho}{2} \frac{l_{\mathrm{c}}}{r_{\mathrm{f}}}(1-\eta)\right)-1\right]-\left(\alpha_{\mathrm{c}}-\alpha_{\mathrm{f}}\right) \Delta \mathrm{T}, \eta<1 \\
\frac{\Phi}{E_{\mathrm{f}}}-\frac{\tau_{\mathrm{i}}}{E_{\mathrm{f}}} \frac{l_{\mathrm{c}}}{2 r_{\mathrm{f}}}-\left(\alpha_{\mathrm{c}}-\alpha_{\mathrm{f}}\right) \Delta \mathrm{T}, \eta=1
\end{array}\right.
$$

where $\Phi$ is the intact fiber stress. The Global Load Sharing (GLS) criterion is adopted to determine the stress distribution between the intact and failure fibers [[21]]

$$
\frac{\sigma}{V_{\mathrm{f}}}=\Phi(1-P)+\frac{2 \tau_{\mathrm{i}}}{r_{\mathrm{f}}}\langle L\rangle P
$$

where $\langle L\rangle$ is the average fiber pullout length, $P$ is the fiber's failure probability.

$$
P=1-\exp \left[-\left(\frac{\Phi}{\sigma_{\mathrm{fc}}}\right)^{m_{\mathrm{f}}+1}\right]
$$

where $\sigma_{\mathrm{fc}}$ is the fiber characteristic strength, and $m_{\mathrm{f}}$ is the fiber Weibull modulus.

\section{Results and discussions}

In this section, experimental monotonic and compliance tensile behavior of $\mathrm{SiC} / \mathrm{SiC}$ minicomposites with and without BNNTs are conducted. The mechanical properties of composite's Young's modulus, fracture strength, and failure strain are obtained. The cyclic loading/unloading inverse tangent modulus (ITM) corresponding to different tensile peak stresses are analyzed. The fracture surfaces of the SiC/SiC minicomposites with and without BNNTs are analyzed under SEM. Using the developed micromechanical constitutive model, the tensile properties of the SiC/SiC minicomposites with and without BNNTs are also predicted. 


\subsection{Monitonic and cyclic loading/unloading tensile of $\mathrm{SiC} / \mathrm{SiC}$ minicomposites with and without BNNTs}

Fig. 4 shows the monotonic tensile stress-strain curves of $\mathrm{SiC} / \mathrm{SiC}$ minicomposite with and without BNNTs. Tensile stress-strain curves exhibited obvious nonlinear mechanical behavior due to the internal damage evolution. Table 2 and 3 listed the tensile mechanical properties of $\mathrm{SiC} / \mathrm{SiC}$ minicomposites with and without BNNTs.

- For $\mathrm{SiC} / \mathrm{SiC}$ minicomposite with BNNTs, four specimens were tensile tested to fracture, and the composite's tensile elastic modulus was $E_{\mathrm{c}}=71,70.2,71.5$, and 83.5 GPa, respectively, the composite's tensile strength was $\sigma_{\mathrm{UTS}}=262.8$, 258.3, 253.5, and 268.1 MPa, respectively, and the corresponding fracture strain was $\varepsilon_{\mathrm{f}}=0.374,0.366,0.383$, and $0.366 \%$, respectively. The average composite elastic modulus was approximately $E_{\mathrm{c}}=74 \mathrm{GPa}$ with the standard deviation of $5.47 \mathrm{GPa}$. The average tensile strength was approximately outs = 260.6 MPa with the standard deviation of 5.4 MPa. The average composite tensile fracture strain was approximately $\varepsilon_{\mathrm{f}}=0.372 \%$ with the standard deviation of $0.007 \%$.

- For $\mathrm{SiC} / \mathrm{SiC}$ minicomposites without BNNTs, four specimens were tensile tested to fracture, and the composite's tensile elastic modulus was $E_{\mathrm{c}}=90.2$, 92.4, 95.9, and 92.1 GPa, respectively, the composite's tensile strength was бuts $=485.6,502.6,482.9$, and $507.8 \mathrm{MPa}$, respectively, and the corresponding tensile fracture strain was $\varepsilon_{\mathrm{f}}=0.658,0.683,0.642,0.648 \%$, respectively. The average composite's elastic modulus was approximately $E_{\mathrm{c}}=$ 92.6 GPa with the standard deviation of $2 \mathrm{GPa}$. The average composite's tensile strength was approximately outs $=494.7 \mathrm{MPa}$ with the standard deviation of 10.7 MPa. The average composite's tensile fracture strain was approximately $\varepsilon_{\mathrm{f}}=0.657 \%$ with the standard deviation of $0.015 \%$. 

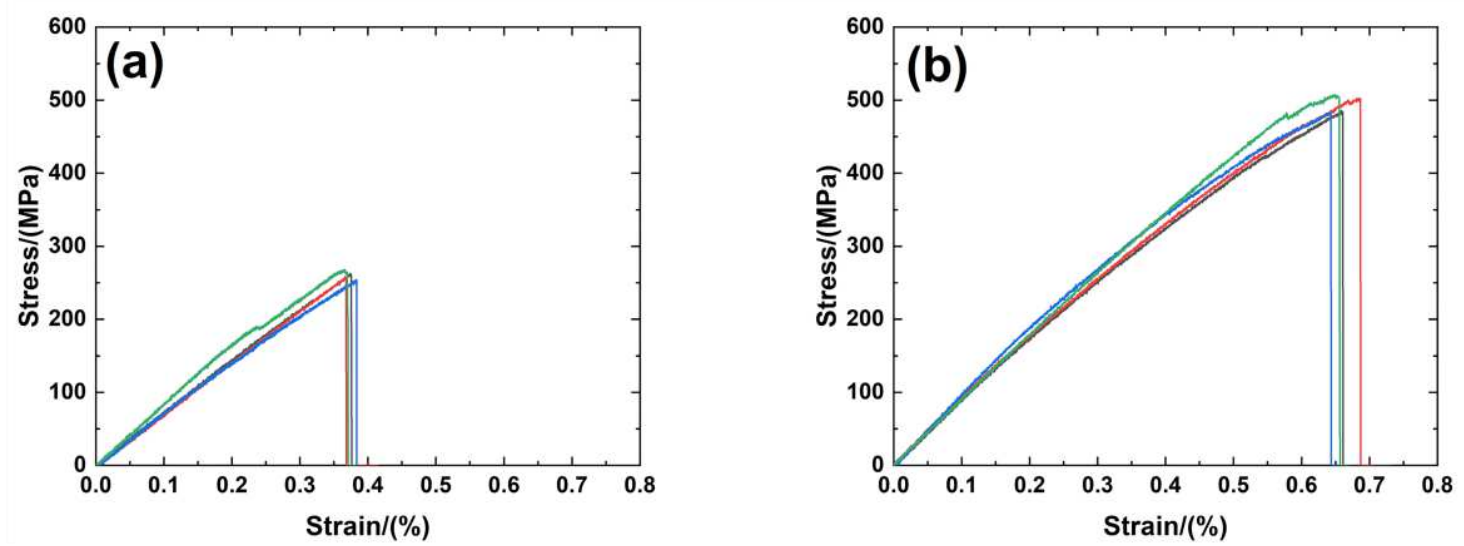

Fig. 4. Monotonic tensile stress-strain curves of $\mathrm{SiC} / \mathrm{SiC}$ minicomposites (a) with BNNTs; and (b) without BNNTs

Table 2. Monotonic tensile properties of $\mathrm{SiC} / \mathrm{SiC}$ minicomposites with BNNTs

\begin{tabular}{cccc}
\hline Specimen & Elastic modulus/(GPa) & Tensile strength/(MPa) & Fracture strain/(\%) \\
\hline$\# 1$ & 71 & 262.8 & 0.374 \\
$\# 2$ & 70.2 & 258.3 & 0.366 \\
$\# 3$ & 71.5 & 253.5 & 0.383 \\
$\# 4$ & 83.5 & 268.1 & 0.366 \\
Average value & 74 & 260.6 & 0.372 \\
Standard deviation & 5.47 & 5.4 & 0.007 \\
\hline
\end{tabular}

Table 3. Monotonic tensile properties of $\mathrm{SiC} / \mathrm{SiC}$ minicomposites without BNNTs

\begin{tabular}{cccc}
\hline Specimen & Elastic modulus/(GPa) & Tensile strength/(MPa) & Fracture strain/(\%) \\
\hline$\# 1$ & 90.2 & 485.6 & 0.658 \\
$\# 2$ & 92.4 & 502.6 & 0.683 \\
$\# 3$ & 95.9 & 482.9 & 0.642 \\
$\# 4$ & 92.1 & 507.8 & 0.648 \\
Average value & 92.6 & 494.7 & 0.657 \\
Standard deviation & 2 & 10.7 & 0.015 \\
\hline
\end{tabular}

It can be found that the composite's elastic modulus, tensile strength, and fracture strain of $\mathrm{SiC} / \mathrm{SiC}$ minicomposites with BNNTs are all less than those of $\mathrm{SiC} / \mathrm{SiC}$ minicomposites without BNNTs. The degradation of the mechanical properties of $\mathrm{SiC} / \mathrm{SiC}$ minicomposites with BNNTs is mainly attributed to the annealing at $1300{ }^{\circ} \mathrm{C}$. In order to show the effect of annealing at $1300{ }^{\circ} \mathrm{C}$ on composite's mechanical properties. The $\mathrm{SiC} / \mathrm{SiC}$ composite without BNNTs were also heat-treated at $1300{ }^{\circ} \mathrm{C}$. 
Fig. 5 shows the typical tensile stress-strain curve. The composite's tensile strength was approximately $\sigma_{\mathrm{UTS}}=163 \mathrm{MPa}$, and the corresponding fracture strain was approximately $\varepsilon_{\mathrm{f}}=0.31 \%$. It can be found that after heat-treatment at $1300{ }^{\circ} \mathrm{C}$, the mechanical properties of the $\mathrm{SiC} / \mathrm{SiC}$ minicomposite degraded rapidly and were less than the values of $\mathrm{SiC} / \mathrm{SiC}$ minicomposite with BNNTs.

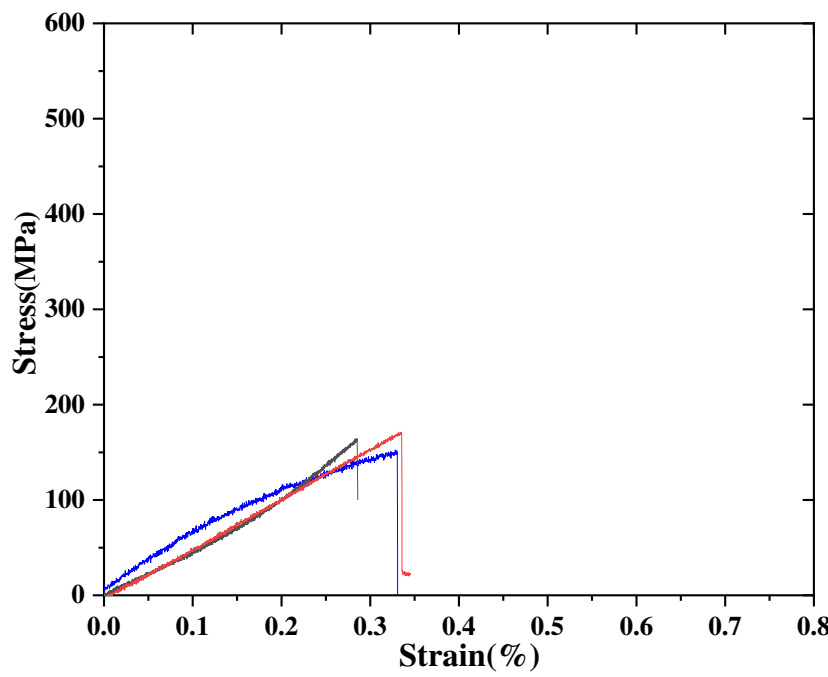

Fig. 5. Tensile stress-strain curve of $\mathrm{SiC} / \mathrm{SiC}$ minicomposite after heat-treatment at $1300{ }^{\circ} \mathrm{C}$

Fig. 6 shows the compliance tensile behavior of $\mathrm{SiC} / \mathrm{SiC}$ minicomposite with and without BNNTs. Three specimens were conducted to the cyclic loading/unloading tests. For SiC/SiC with BNNTs, under tensile loading, the specimen was unloading at the peak stresses of $\sigma_{\max }=75,125$, and $175 \mathrm{MPa}$ to the valley stress of $\sigma_{\min }=20 \mathrm{MPa}$, respectively, and then loading to final fracture. For SiC/SiC without BNNTs, under tensile loading, the specimen was unloading at different peak stresses of $\sigma_{\max }=150,250$, and $350 \mathrm{MPa}$ to the valley stress of $\sigma_{\min }=20 \mathrm{MPa}$, and then tensile to final fracture.

- For $\mathrm{SiC} / \mathrm{SiC}$ minicomposite with BNNTs, the unloading and reloading hysteresis loops exhibited non-closure appearance at peak and valley stress, and there is almost no permanent strain. However, for $\mathrm{SiC} / \mathrm{SiC}$ minicomposite without BNNTs, the unloading and reloading hysteresis loops exhibited closure at the valley stress and non-closure at the peak stress, and there is clear permanent strain [[22]].

- For $\mathrm{SiC} / \mathrm{SiC}$ minicomposite with BNNTs, the peak strains at the peak stresses of $\sigma_{\max }=75,125$, and $175 \mathrm{MPa}$ were $\varepsilon_{\mathrm{c}}=0.096,0.158$, and $0.225 \%$, and the 
composite tensile fracture occurred at the stress of $\sigma \mathrm{vTs}=288.7 \mathrm{MPa}$ with the fracture strain of $\varepsilon_{\mathrm{f}}=0.42 \%$.

- For $\mathrm{SiC} / \mathrm{SiC}$ minicomposite without BNNTs, the peak strains at the peak stresses of $\sigma_{\max }=150,250$, and $350 \mathrm{MPa}$ were $\varepsilon_{\mathrm{c}}=0.199,0.361$, and $0.523 \%$, and the composite tensile fracture occurred at the stress of $\sigma \mathrm{uTs}=524 \mathrm{MPa}$ with the fracture strain of $\varepsilon_{\mathrm{f}}=0.86 \%$.
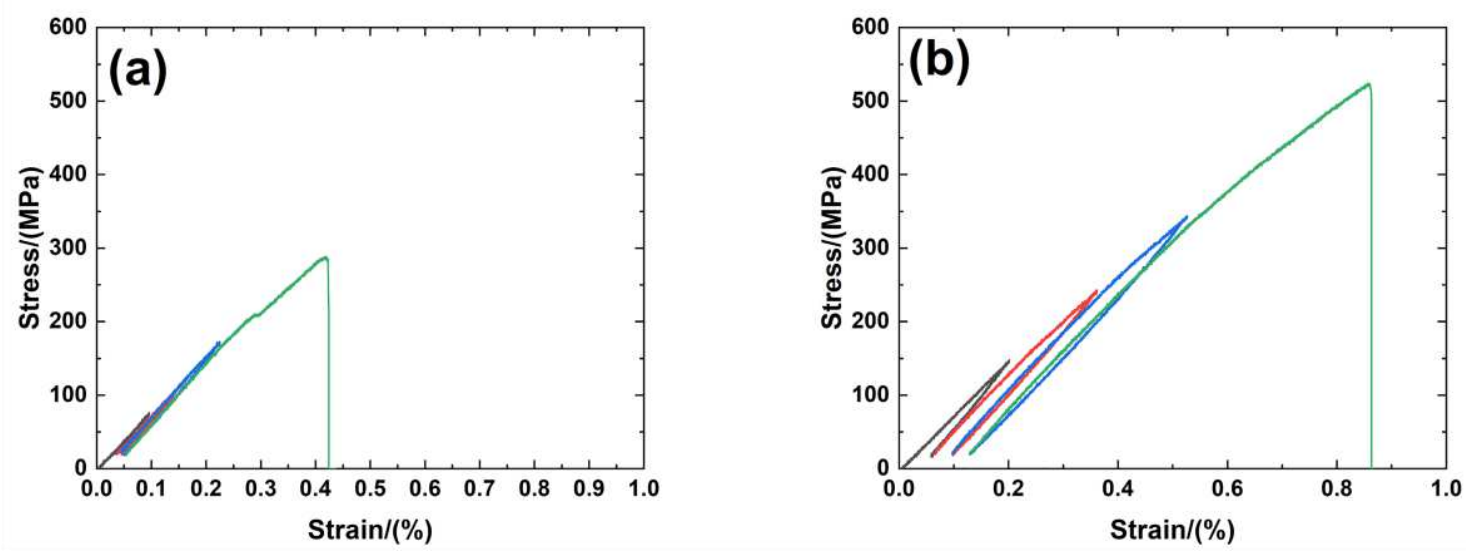

Fig. 6. Cyclic compliance tensile curves of SiC/SiC minicomposites (a) with BNNTs; and (b) without BNNTs

Fig.s 7 and 8 show the loading and unloading inverse tangent modulus (ITM) versus applied stress curves of $\mathrm{SiC} / \mathrm{SiC}$ minicomposites with and without BNNTs.

- For $\mathrm{SiC} / \mathrm{SiC}$ minicomposite with BNNTs, the loading ITM increased with increasing applied stress and then remained constant. However, when the peak stress increased from $\sigma_{\max }=75$ to $175 \mathrm{MPa}$, the constant ITM decreased from 12.6 $\mathrm{TPa}^{-1}$ to $12.1 \mathrm{TPa}^{-1}$. The unloading ITM increased with decreasing applied stress to the constant value. When the peak stress increased from $\sigma_{\max }$ $=75$ to $175 \mathrm{MPa}$, the constant ITM increased from $10.8 \mathrm{TPa}^{-1}$ to $11.2 \mathrm{TPa}^{-1}$.

- For SiC/SiC minicomposite without BNNTs, the loading ITM increased with increasing applied stress and then remained constant. However, when the peak stress increased from $\sigma_{\max }=150$ to $350 \mathrm{MPa}$, the constant ITM decreased from 13.6 $\mathrm{TPa}^{-1}$ to $13.2 \mathrm{TPa}^{-1}$. The unloading ITM increased with decreasing applied stress to the constant value. When the peak stress increased from $\sigma_{\max }$ $=150$ to $350 \mathrm{MPa}$, the constant ITM increased from $10.8 \mathrm{TPa}^{-1}$ to $12.3 \mathrm{TPa}^{-1}$. 

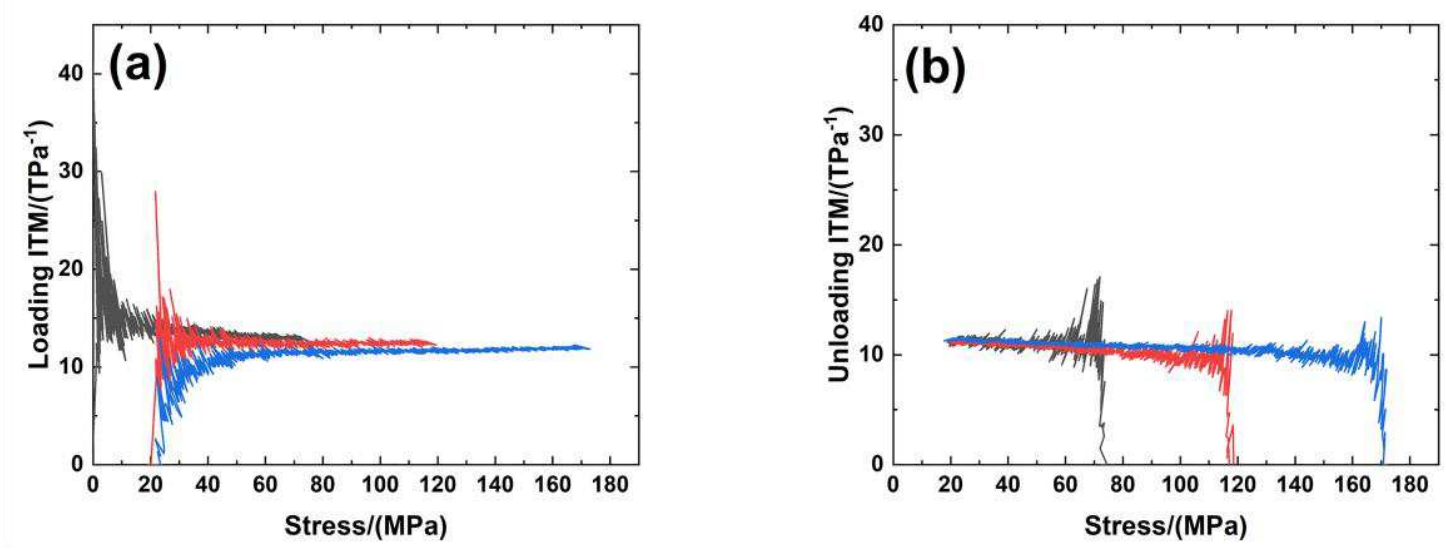

Fig. 7. (a) Loading ITM; and (b) unloading ITM versus applied stress curves of $\mathrm{SiC} / \mathrm{SiC}$ minicomposite with BNNTs for different peak stresses of $\sigma_{\max }=75,125$, and $175 \mathrm{MPa}$
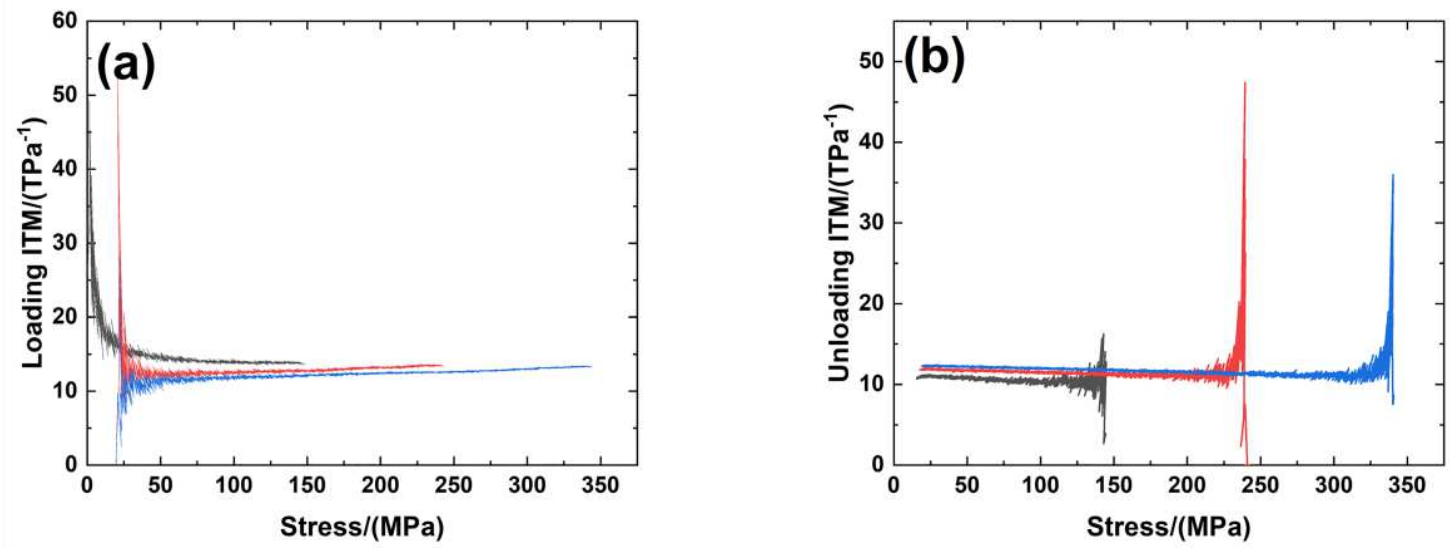

Fig. 8. (a) Loading ITM; and (b) unloading ITM versus applied stress curves of SiC/SiC minicomposite without BNNTs for different peak stresses of $\sigma_{\max }=150,250$, and $350 \mathrm{MPa}$

\subsection{Original and fracture surface observation of $\mathrm{SiC} / \mathrm{SiC}$ minicomposites with and without BNNTs under SEM}

Using ball milling - annealing process, the in situ BNNTs were grown on the surface of SiC fibers. Fig. 9 shows the microstructure of the surface of SiC fibers with BNNTs under SEM. It can be found that the BNNTs were successfully grown on the surface of SiC fibers, and the grown was compact and evenly covered on the fibers' surface. 


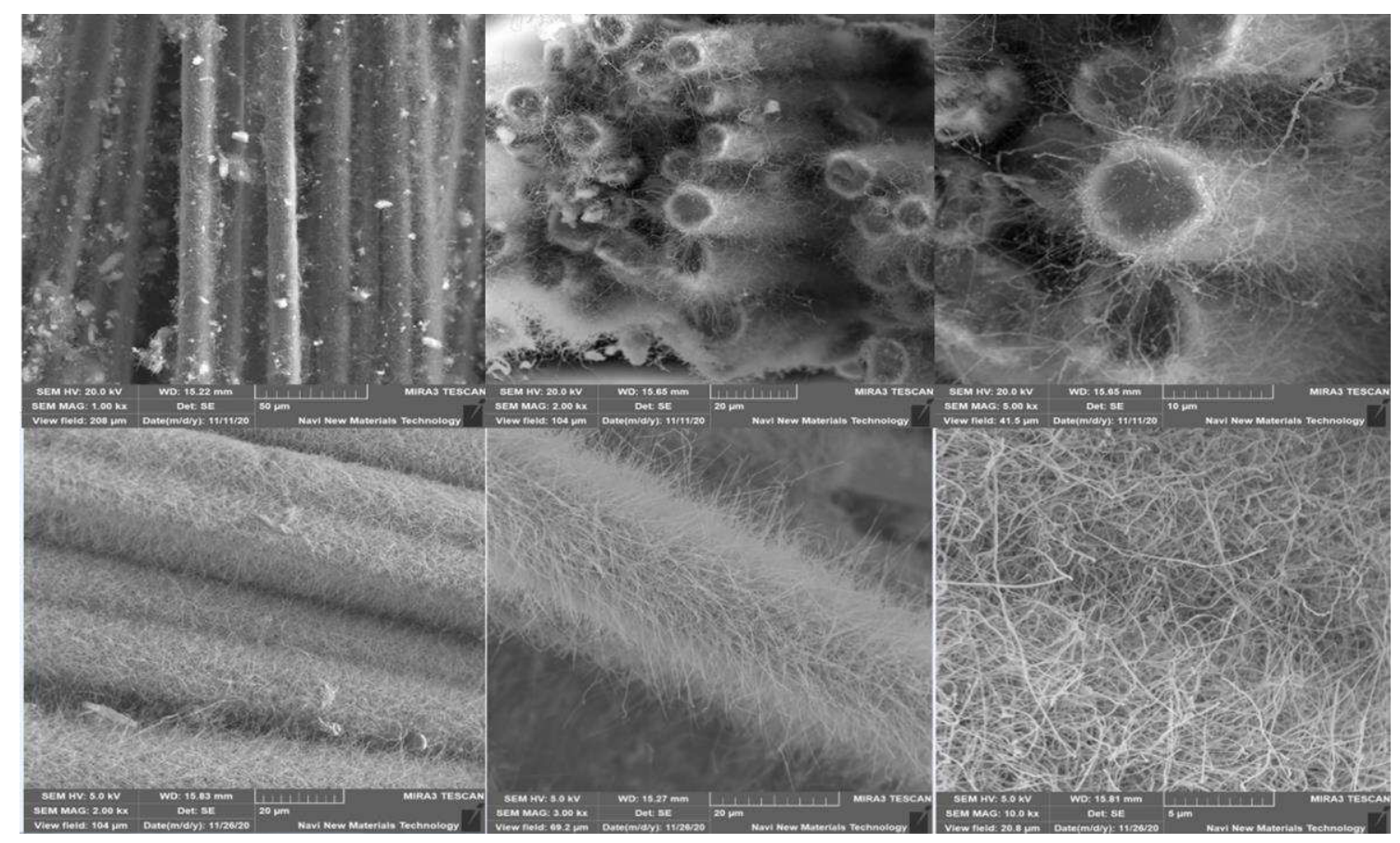

Fig. 9. Microstructure observation on surface of SiC fibers with BNNTs under SEM

The element analysis was performed for the SiC fibers' surface, as shown in Fig. 10. It was found that $\mathrm{B}$ and $\mathrm{N}$ are the main elements on the surface, in addition, a small amount of $\mathrm{Fe}$ and $\mathrm{Mg}$ also existed. Table 4 shows the ratio of different elements, including: $\mathrm{B}, \mathrm{N}, \mathrm{Si}, \mathrm{C}, \mathrm{O}, \mathrm{Mg}$, and $\mathrm{Fe}$.

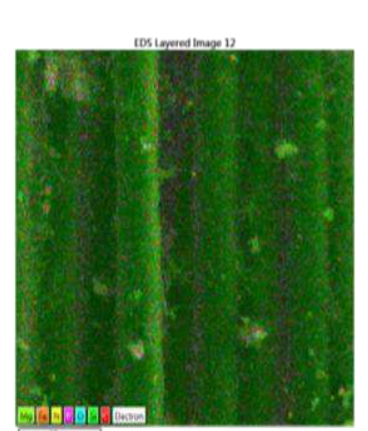

$\mathrm{C} K \alpha 12$

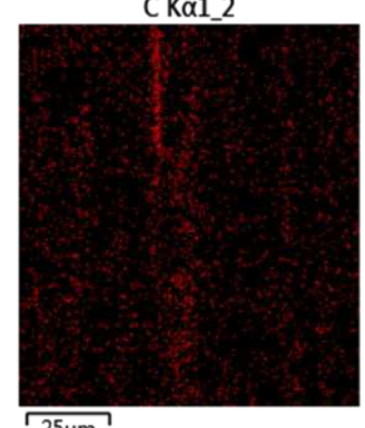

$\widehat{25 \mu m}$
$\mathrm{N} \mathrm{K \alpha 12}$

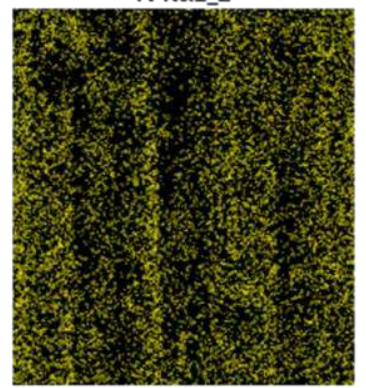

$25 \mu \mathrm{m}$

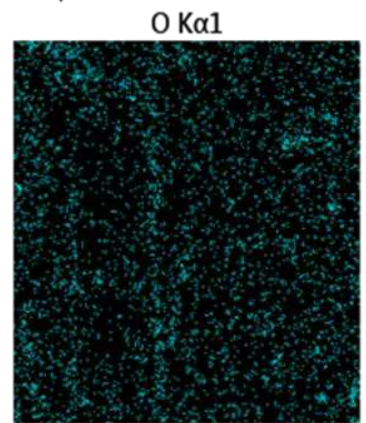

$\sqrt{25 \mu \mathrm{m}}$
$\mathrm{BK} \alpha 12$

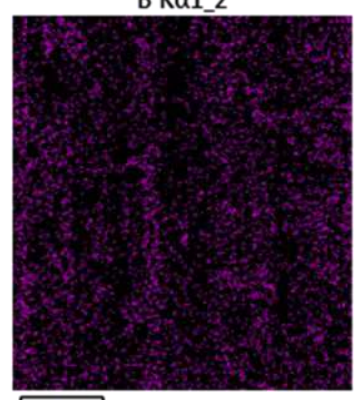

$25 \mu \mathrm{m}$

$\mathrm{Mg} \mathrm{K} \alpha 12$

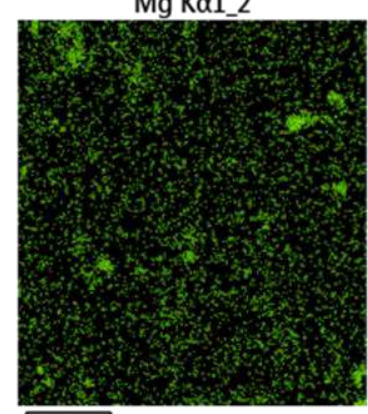

$\longdiv { 2 5 \mu \mathrm { m } }$
Si $K \alpha 1$

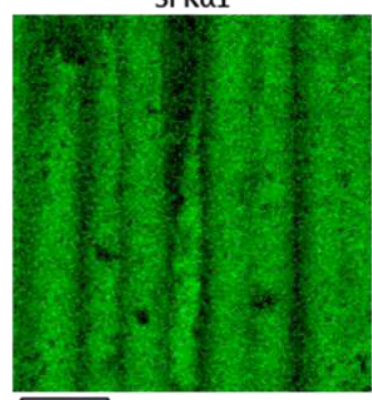

$25 \mu \mathrm{m}$

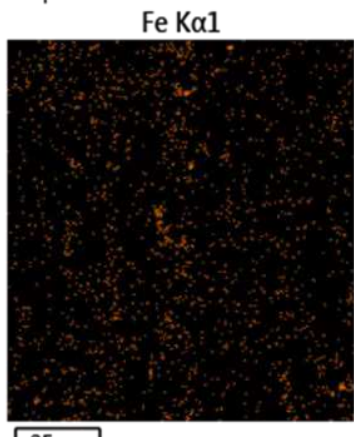

$\sqrt{25 \mu \mathrm{m}}$

Fig. 10. Element analysis of SiC fiber with BNNTs. 
Table 4. Ratio of different elements of SiC fiber with BNNTs

\begin{tabular}{cccccccc}
\hline Element & $\mathbf{B}$ & $\mathbf{N}$ & $\mathbf{S i}$ & $\mathbf{C}$ & $\mathbf{O}$ & $\mathbf{M g}$ & $\mathbf{F e}$ \\
\hline Weight \% & 39.1 & 30.5 & 12.5 & 11.5 & 5.3 & 0.6 & 0.5 \\
\hline
\end{tabular}

Fig.s 11 and 12 show the fracture morphology of $\mathrm{SiC} / \mathrm{SiC}$ minicomposites with and without BNNTs. For SiC/SiC minicomposite with BNNTs, the pullout length of the $\mathrm{SiC}$ fiber was short, and the fracture surface was planar. There is no obvious PyC interphase on the $\mathrm{SiC}$ fibers' surface. During the annealing at approximately $1300{ }^{\circ} \mathrm{C}$, the PyC interphase may oxidize with $\mathrm{O}_{2}$. Without the interphase, the composite exhibited low tensile fracture strength and failure strain. For $\mathrm{SiC} / \mathrm{SiC}$ minicomposite without BNNTs, the PyC interface existed on the surface of SiC fibers with the thickness of approximately $150-200 \mathrm{~nm}$. The interphase plays function of load transfer between the fiber and the matrix and leads to long fiber's pullout length. The mechanical properties of $\mathrm{SiC} / \mathrm{SiC}$ minicomposite without BNNTs is better than that of $\mathrm{SiC} / \mathrm{SiC}$ minicomposite with BNNTs. To illustrate the effect of annealing at elevated temperature on composite's mechanical properties, Fig. 13 shows the fracture morphology of $\mathrm{SiC} / \mathrm{SiC}$ minicomposite after heat-treatment at $1300{ }^{\circ} \mathrm{C}$. It can be found that the fracture surface of the composite was planar, and few fiber's pullout appeared. 


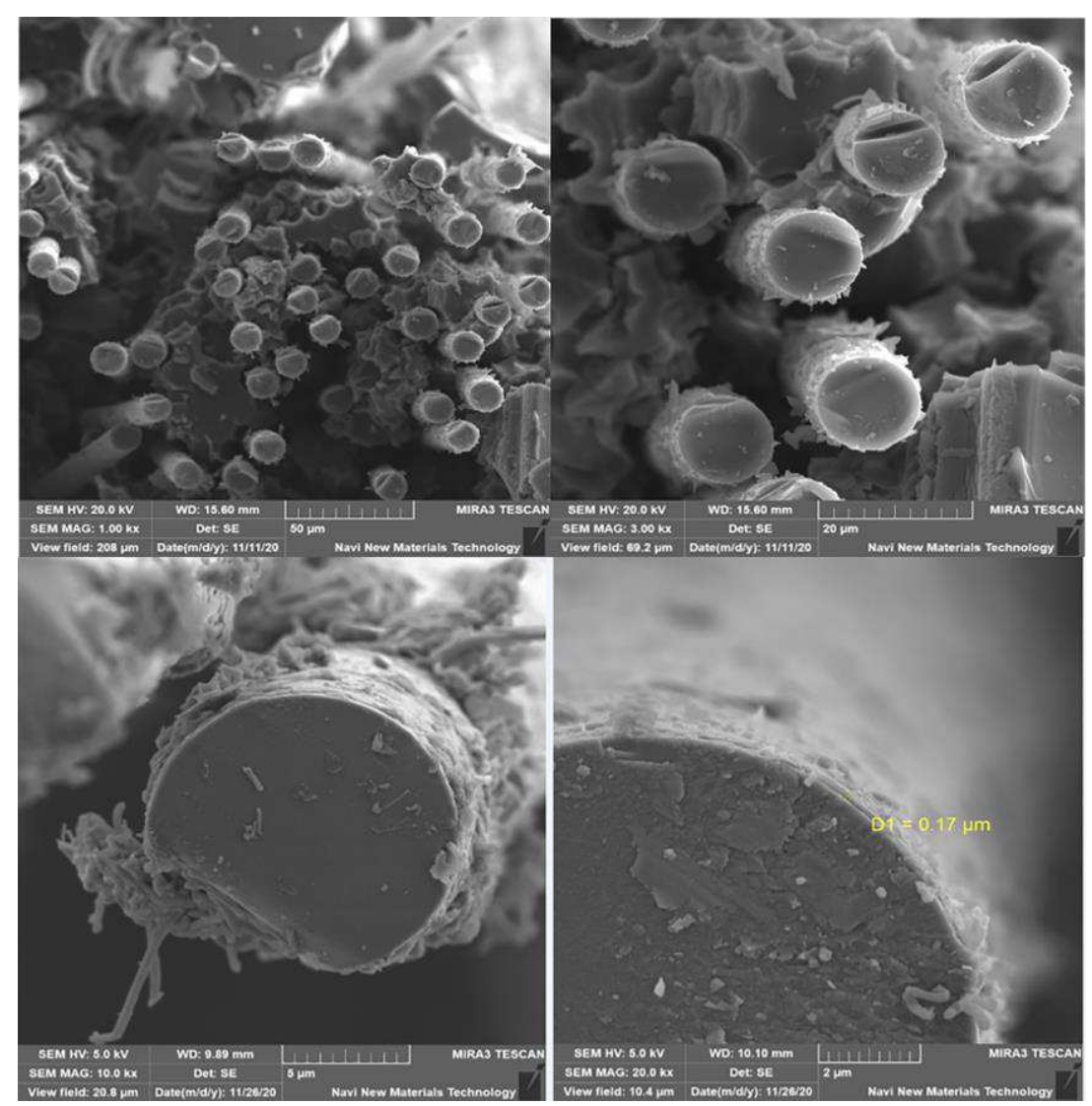

Fig. 11. Fracture morphology of $\mathrm{SiC} / \mathrm{SiC}$ minicomposite with BNNTs.

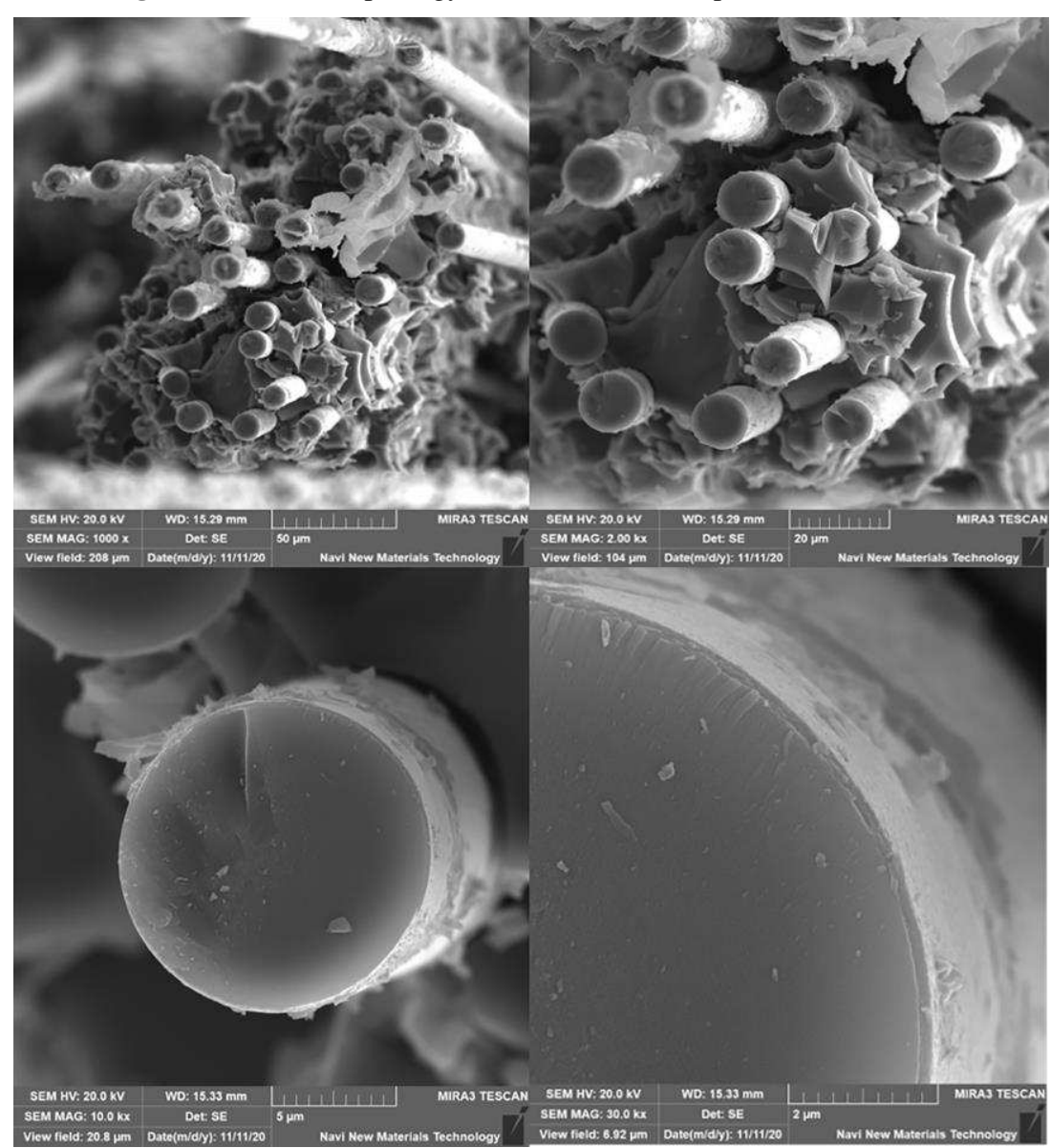

Fig. 12. Fracture morphology of $\mathrm{SiC} / \mathrm{SiC}$ minicomposite without BNNTs. 


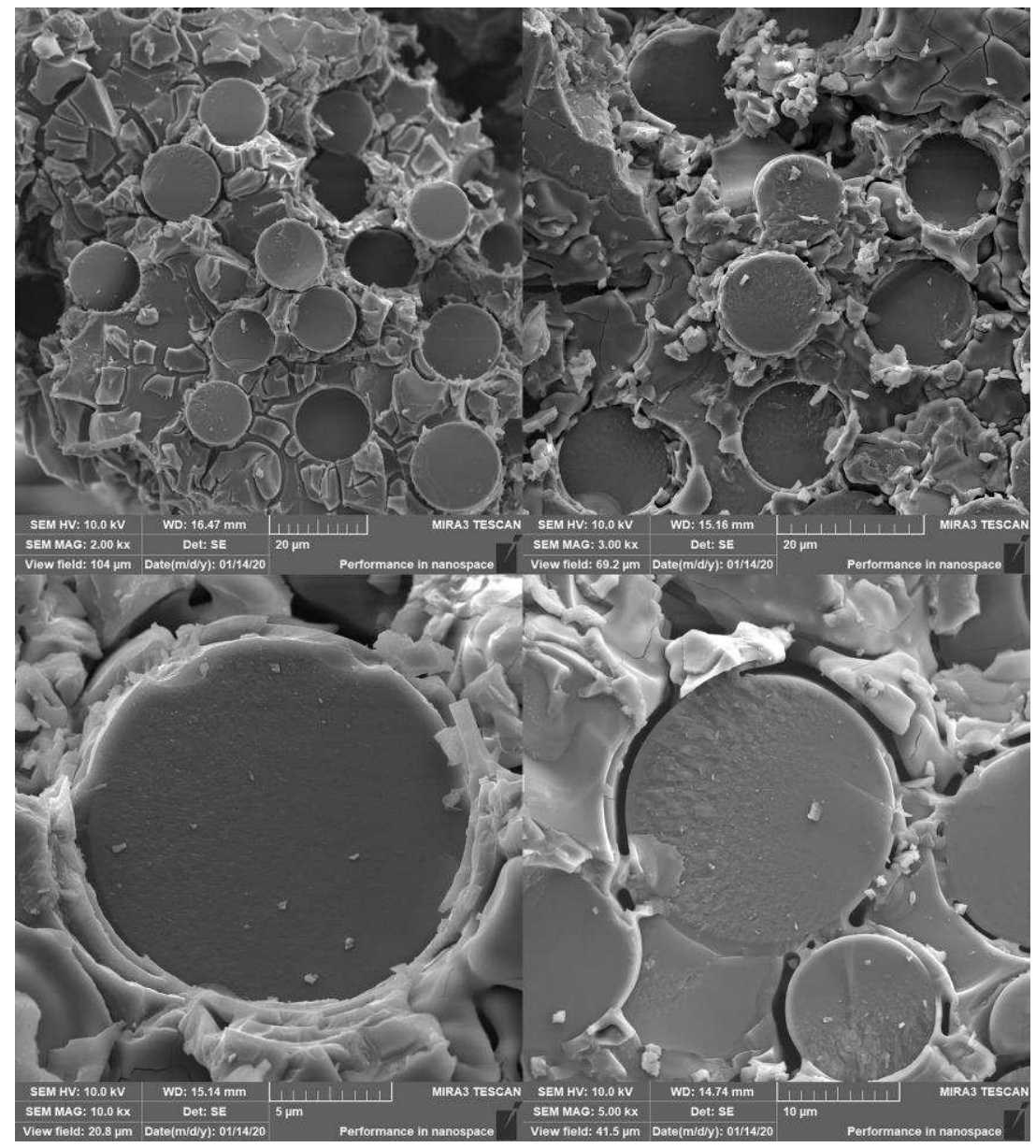

Fig. 13. Fracture morphology of $\mathrm{SiC} / \mathrm{SiC}$ minicomposite after heat-treatment at $1300{ }^{\circ} \mathrm{C}$.

\subsection{Experimental comparisons}

Under tensile loading, nonlinear behavior appears for the $\mathrm{SiC} / \mathrm{SiC}$ minicomposite with and without BNNTs. In the section 3, a micromechanical constitutive relationship is developed considering different damage mechanisms occurred in the composites under tensile loading. The nonlinear stress-strain curves of $\mathrm{SiC} / \mathrm{SiC}$ minicomposite with and without BNNTs can be predicted using the developed constitutive models. The evolution of broken fiber fraction versus applied strain can also be predicted.

Fig. 14 shows experimental and predicted tensile stress-strain curves and broken fiber fraction versus strain curves of $\mathrm{SiC} / \mathrm{SiC}$ minicomposite with BNNTs. Considering multiple micro damage mechanisms of matrix fragmentation, interface debonding, and fiber fragmentation, the predicted tensile stress-strain curves agreed with experimental data. Under tensile loading, fibers' failure occurred at applied strain of approximately $\varepsilon_{\mathrm{c}}$ $=0.15 \%$; and approached tensile fracture, the broken fiber fraction lied in the range of $P$ $=0.35-0.48 \%$. 
Fig. 15 shows experimental and predicted composite's tangent modulus versus applied stress curves of SiC/SiC minicomposite with BNNTs. With increasing tensile stress, the composite's tangent modulus decreased from approximately $E_{\mathrm{P}}=82$ to 52 $\mathrm{GPa}$.

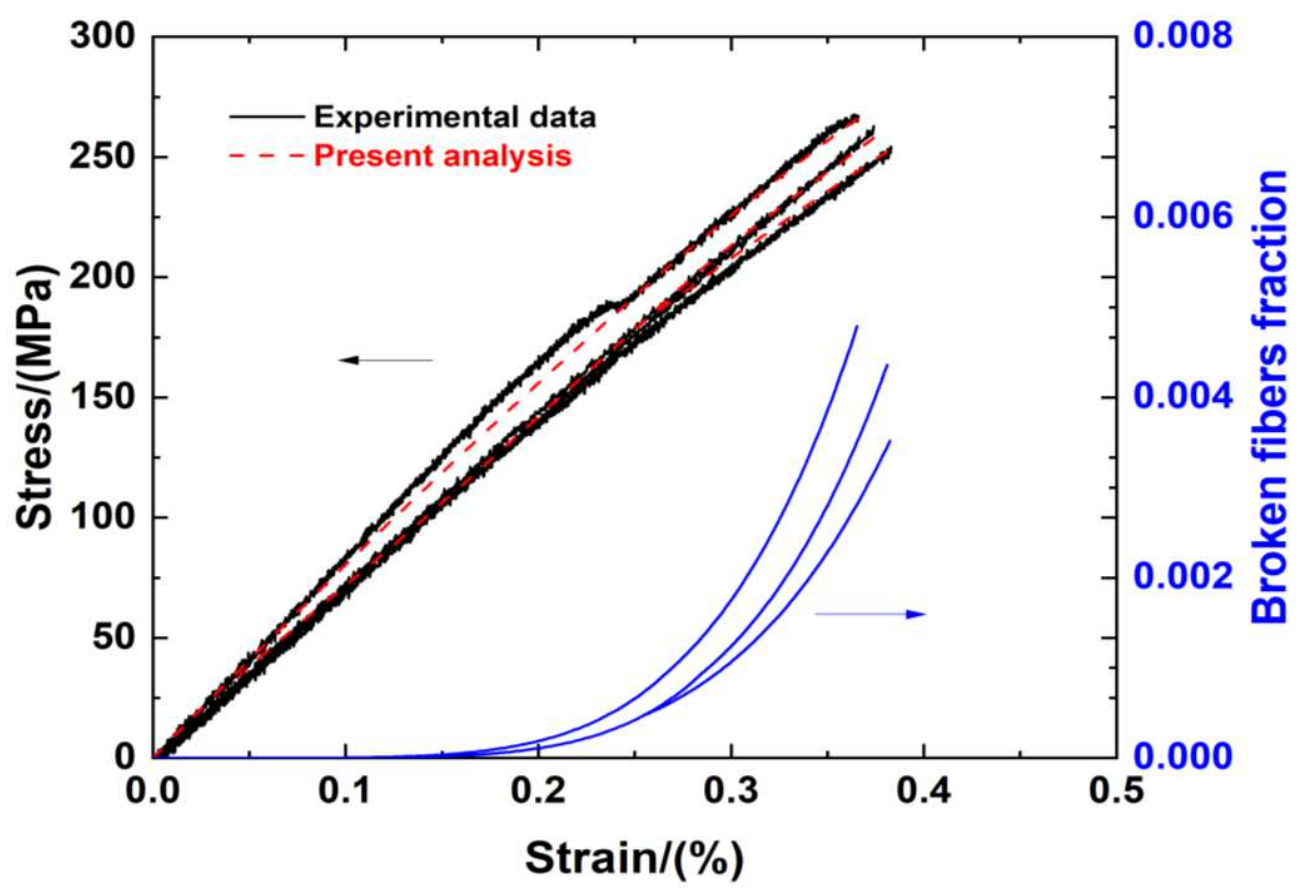

Fig. 14. Experimental and predicted tensile stress-strain curves and broken fiber fraction versus applied strain curves of $\mathrm{SiC} / \mathrm{SiC}$ minicomposites with BNNTs. 

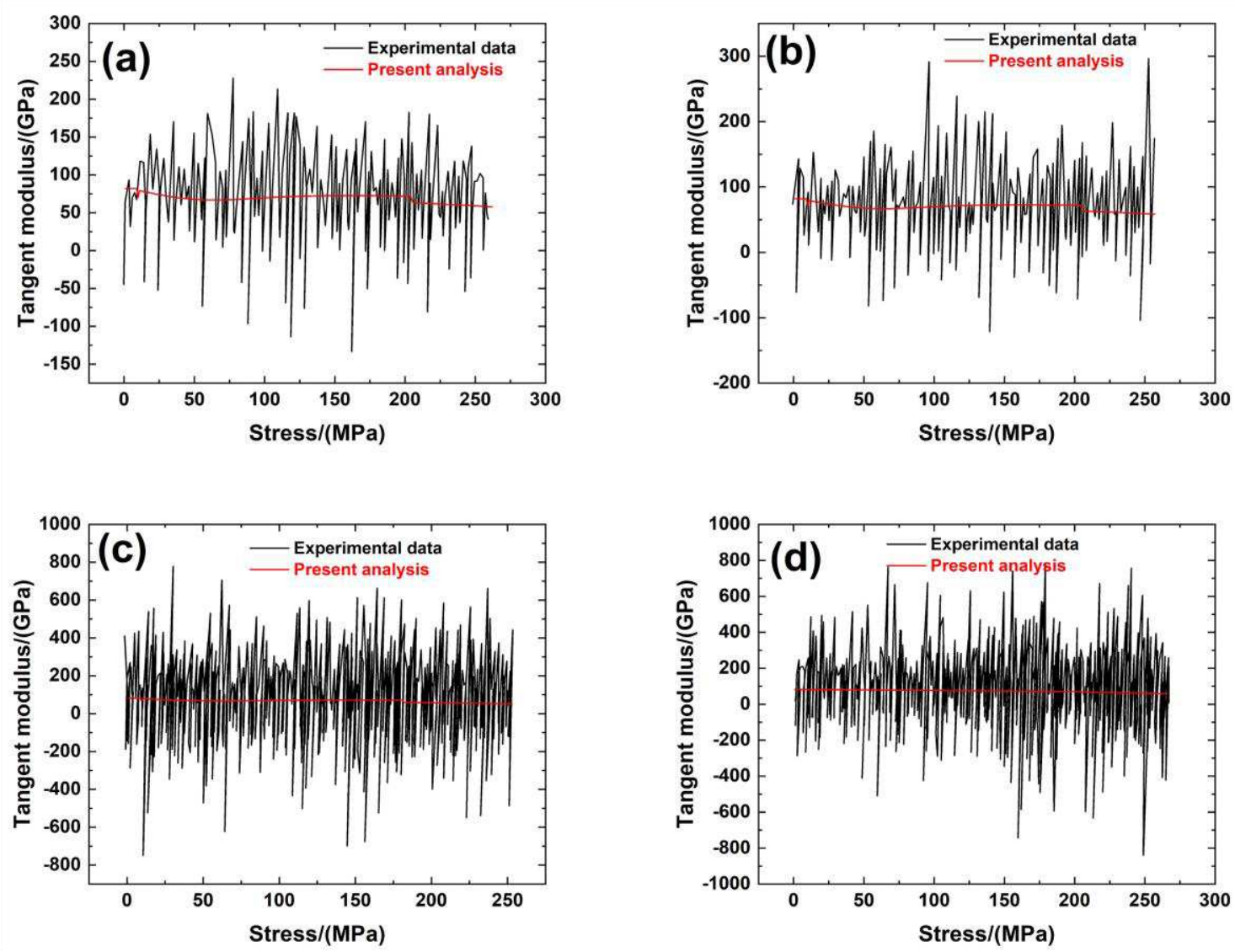

Fig. 15. Experimental and predicted composite's tangent modulus versus applied stress curves of $\mathrm{SiC} / \mathrm{SiC}$ minicomposite with BNNTs.

Fig. 16 shows experimental and predicted tensile stress-strain curves and broken fiber fraction versus applied strain curves of $\mathrm{SiC} / \mathrm{SiC}$ minicomposite without BNNTs. Considering multiple damage mechanisms of matrix fragmentation, interface debonding, and fiber fragmentation, the predicted tensile stress-strain curves agreed with experimental data. Under tensile loading, fibers' failure occurred at applied strain of approximately $\varepsilon_{\mathrm{c}}=0.15 \%$, and approached tensile fracture, the broken fiber fraction lied in the range of $P=1.6-2.2 \%$.

Fig. 17 shows experimental and predicted composite's tangent modulus versus applied stress curves of $\mathrm{SiC} / \mathrm{SiC}$ minicomposite without BNNTs. With increasing tensile stress, the composite's tangent modulus decreased from approximately $E_{\mathrm{P}}=93$ to $50.2 \mathrm{GPa}$. 


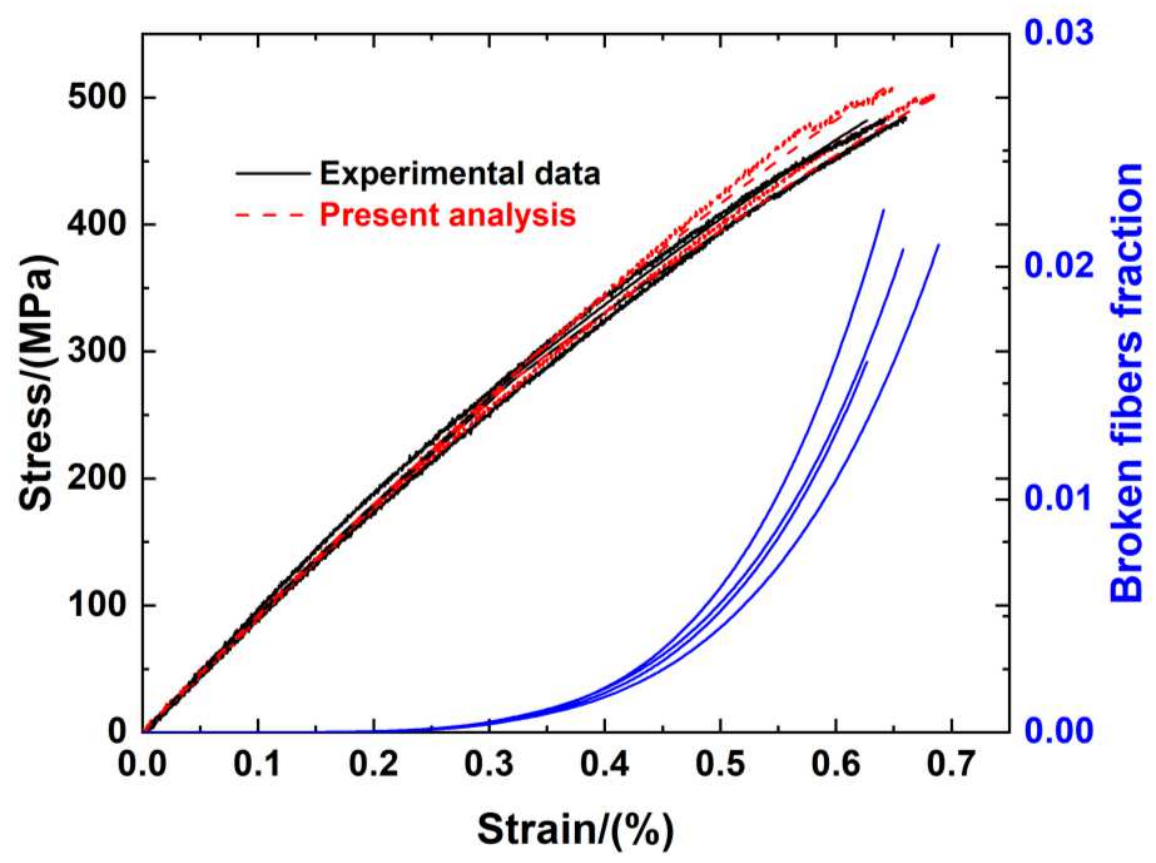

Fig. 16. Experimental and predicted tensile stress-strain curves and broken fiber fraction versus applied strain curves of $\mathrm{SiC} / \mathrm{SiC}$ minicomposites without BNNTs.
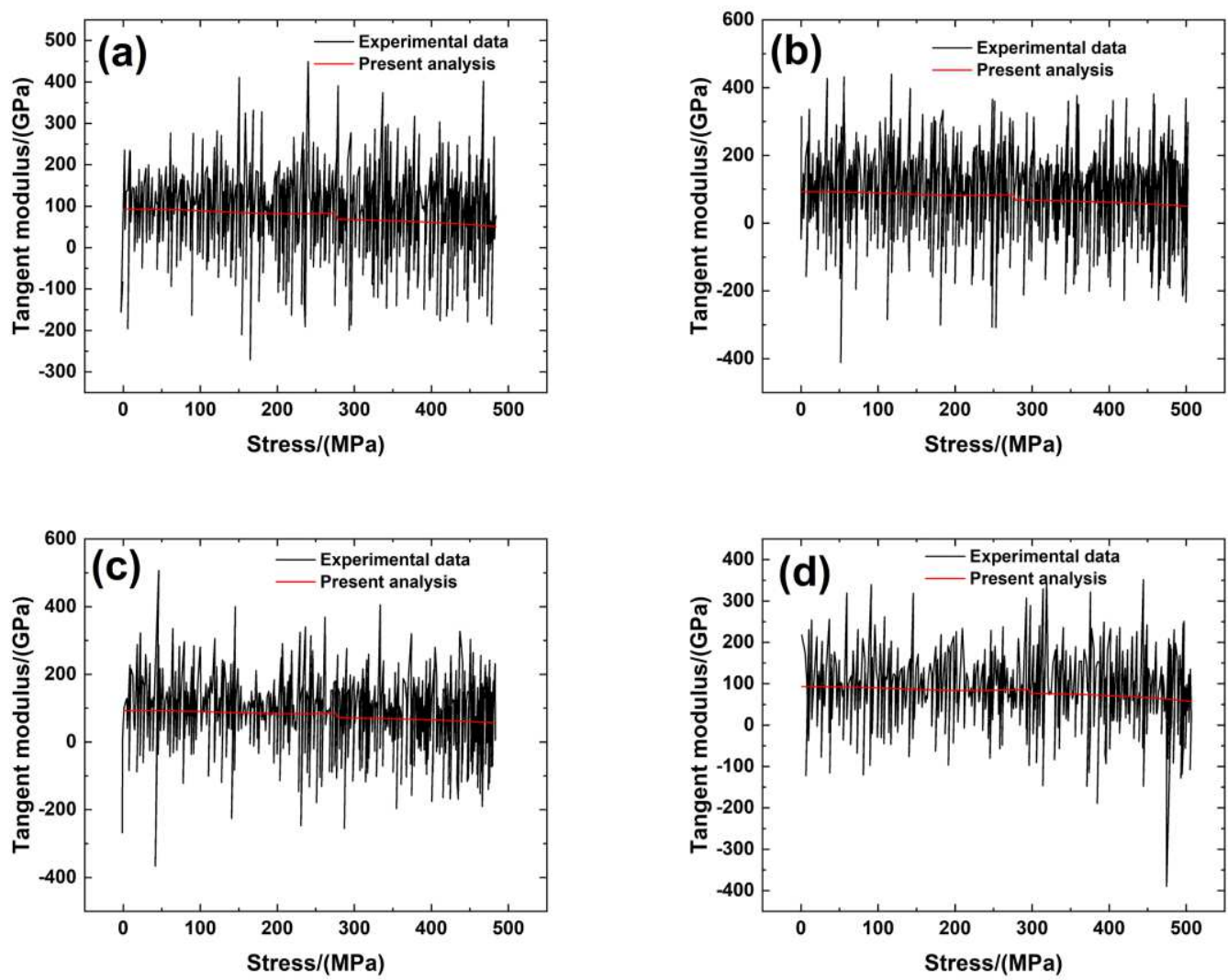

Fig. 17. Experimental and predicted composite's tangent modulus versus applied stress curves of $\mathrm{SiC} / \mathrm{SiC}$ minicomposite without BNNTs. 


\section{Conclusions}

In this paper, the $\mathrm{SiC} / \mathrm{SiC}$ minicomposites with and without BNNTs were fabricated by using the PIP method. Effect of in situ grown BNNTs on monotonic tensile and compliance tensile behavior was analyzed. Mechanical properties of composite's elastic modulus, tensile strength, and fracture strain under tensile loading were obtained. Under cyclic compliance tensile, the ITMs for different peak stresses were also analyzed. After tensile fracture, the specimens were observed under SEM to reveal internal damage mechanisms. Experimental tensile stress-strain curves, broken fiber fraction, and composite's tangent modulus were predicted using the developed micromechanical constitutive model.

- Under monotonic tensile loading, for $\mathrm{SiC} / \mathrm{SiC}$ minicomposite with BNNTs, the average composite tensile elastic modulus was approximately $E_{\mathrm{c}}=74 \mathrm{GPa}$, the average composite tensile strength was approximately $\sigma_{\mathrm{UTS}}=260.6 \mathrm{MPa}$, and the composite's fracture strain lied in the range between $\varepsilon_{\mathrm{f}}=0.366$ and $0.383 \%$; for the $\mathrm{SiC} / \mathrm{SiC}$ minicomposites without BNNTs, the average composite's tensile elastic modulus was approximately $E_{\mathrm{c}}=92.6 \mathrm{GPa}$, the average composite tensile strength was approximately outs $=494.7 \mathrm{MPa}$, and the tensile fracture strain lied in the range between $\varepsilon_{\mathrm{f}}=0.642$ and $0.683 \%$.

- The $\mathrm{SiC} / \mathrm{SiC}$ composite without BNNTs were heat-treated at $1300{ }^{\circ} \mathrm{C}$. The composite's tensile strength was approximately $\sigma_{\mathrm{UTS}}=163 \mathrm{MPa}$, and the corresponding fracture strain was approximately $\varepsilon_{\mathrm{f}}=0.31 \%$. It can be found that after heat-treatment at $1300{ }^{\circ} \mathrm{C}$, the mechanical properties of the $\mathrm{SiC} / \mathrm{SiC}$ minicomposite degraded rapidly and were less than the values of $\mathrm{SiC} / \mathrm{SiC}$ minicomposite with BNNTs.

- Under compliance tensile loading, for $\mathrm{SiC} / \mathrm{SiC}$ minicomposite with and without BNNTs, the loading ITM increased with increasing applied stress and then remained constant. The unloading ITM increased with decreasing applied stress to the constant value.

- At the fracture surface, for SiC/SiC minicomposite with BNNTs, the pullout 
length of the SiC fiber was short. There was no obvious PyC interphase on the SiC fibers' surface. For SiC/SiC minicomposite without BNNTs, the PyC interface existed on the surface of $\mathrm{SiC}$ fibers with the thickness of approximately 150 200 $\mathrm{nm}$. For the $\mathrm{SiC} / \mathrm{SiC}$ minicomposite after heat-treatment at $1300{ }^{\circ} \mathrm{C}$, the fracture surface of the composite was planar, and few fiber's pullout appeared.

\section{Conflict of Interest}

The authors declare that they have no known competing financial interests or personal relationships that could have appeared to influence the work reported in this paper.

\section{Acknowledgements}

The work reported here is supported by the National Natural Science Foundation of China (Grant No. 51902348, 52002403), Open Research Fund Program of Science and Technology on Aerospace Chemical Power Laboratory (Grand No. STACPL120181b05-2) and the Project (ZZYJKT2020-11) of State Key Laboratory of High Performance Complex Manufacturing, Central South University, and the Fundamental Research Funds for the Central Universities of China (Grant No. NS2019038).

\section{References}

[1] Naslain R. Design, Preparation and properties of non-oxide CMCs for application in engines and nuclear reactors: an overview. Compos Sci Technol 2004; 64:155-170. https://doi.org/10.1016/S0266-3538(03)00230-6

[2] Li LB. Damage, fracture and fatigue of ceramic-matrix composites. Springer Nature, Singapore, 2018.

https://www.springer.com/in/book/9789811317828

[3] Li LB. Thermomechanical fatigue of ceramic-matrix composites. Wiley-VCH, Weinheim, 
Germany. 2019.

https://onlinelibrary.wiley.com/doi/book/10.1002/9783527822614

[4] Li LB. Durability of ceramic matrix composites. Woodhead Publishing, Oxford, UK. 2020. https://doi.org/10.1016/C2018-0-03346-0

[5] Naslain R, Lamon J, Pailler R, Bourrat X, Guette A, Langlais F. Micro/minicomposites: a useful approach to the design and development of non-oxide CMCs. Compos Part A 1999; 30:537-547.

https://doi.org/10.1016/S1359-835X(98)00147-X

[6] Golberg D, Bando Y, Tang C, Zhi C. Boron nitride nanotubes. Adv Mater 2007; 19:2413-2432. https://doi.org/10.1002/adma.200700179

[7] Zhi C, Bando Y, Tang C, Golberg D. Boron nitride nanotubes. Mater Sci Eng R 2010; 70:92-111.

https://doi.org/10.1016/j.mser.2010.06.004

[8] Zhi CY, Bando Y, Tang CC, Huang Q, Golberg D. Boron nitride nanotubes: functionalization and composites. J Mater Chem 2008; 18:3900-3908.

https://doi.org/10.1039/B804575E

[9] Bansal NP, hurst JB, Chois R. Boron nitride nanotubes-reinforced glass composites. J Am Ceram Soc 2006; 89:388-390.

https://doi.org/10.1111/j.1551-2916.2005.00701.x

[10] Choi SR, Bansal NP, Garg A. Mechanical and microstructural characterization of boron nitride nanotubes-reinforced SOFC seal glass composite. Mater Sci Eng A 2007; 460:509-515.

https://doi.org/10.1016/j.msea.2007.01.084

[11] Huang Q, Bando YS, Xu X, Nishimura T, Zhi C, Tang C, Xu F, Gao L, Golberg D. Enhancing superplasticity of engineering ceramics by introducing BN nanotubes. Nanotechnology 2007; 18:485706-7.

https://doi.org/10.1088/0957-4484/18/48/485706

[12] Hurst J. Boron nitride nanotubes, silicon carbide nanotunes and carbon nanotubes- a comparison of properties and applications. In: Nanotube Superfiber Materials, Edited by Mark J Schulz, Vesselin N Shanov and Zhangzhang Yin, William Andrew Publishing, 2013. https://doi.org/10.1016/B978-1-4557-7863-8.00009-8 
[13] Li LB, Song Y, Sun Y. Modeling the tensile behavior of unidirectional C/SiC ceramic-matrix composites. Mech Compos Mater 2014; 49:659-672.

https://doi.org/10.1007/s11029-013-9382-y

[14] Li LB. Modeling the monotonic and cyclic tensile stress-strain behavior of 2D and 2.5D woven C/SiC ceramic-matrix composites. Mech Compos Mater 2018; 54:165-178. https://doi.org/10.1111/j.1551-2916.2004.01726.x

[15] Li LB. Effect of stochastic loading on tensile damage and fracture of fiber-reinforced ceramic-matrix composites. Materials 2020; 13:2469.

https://doi.org/10.3390/ma13112469

[16] Li LB. A time-dependent tensile constitutive model for long-fiber-reinforced unidirectional ceramic-matrix minicomposites considering interface and fiber oxidation. Int J Damage Mech 2020; 29:1138-1166.

https://doi.org/10.1177/1056789520924103

[17] Maillet E, Godin N, R'Mili M, Reynaud P, Fantozzi G, Lamon J. Damage monitoring and identification in $\mathrm{SiC} / \mathrm{SiC}$ minicomposites using combined acousto-ultralics and acoustic emission. Compos Part A 2014; 57:8-15.

https://doi.org/10.1016/j.compositesa.2013.10.010

[18] Whitlow T, Jones E, Przybyla C. In-situ damage monitoring of a SiC/SiC ceramic matrix composite using acoustic emission and digital image correlation. Compos Struct 2016; $158: 245-251$.

http://dx.doi.org/10.1016/j.compstruct.2016.09.040

[19] Curtin WA. Multiple matrix cracking in brittle matrix composites. Acta metal mater 1993; 41:1369-1377.

https://doi.org/10.1016/0956-7151(93)90246-O

[20] Gao Y, Mai Y, Cotterell B. Fracture of fiber-reinforced materials. J Appl Math Phys 1988; 39: $550-572$.

https://doi.org/10.1007/BF00948962

[21] Curtin WA. Theory of mechanical properties of ceramic-matrix composites. J Am Ceram Soc $1991 ; 74: 2837-2845$.

https://doi.org/10.1111/j.1151-2916.1991.tb06852.x 
[22] Shi Y, Kessel F, Friess M, Jain N, Tushtev K. Characterization and modeling of tensile properties of continuous fiber reinforced $\mathrm{C} / \mathrm{C}-\mathrm{SiC}$ composite at high temperatures. J Euro Ceram Soc 2021; Online.

https://doi.org/10.1016/j.jeurceramsoc.2020.09.043 


\section{Table captions}

Table 1. General properties of $\mathrm{SiC} / \mathrm{SiC}$ minicomposites.

Table 2. Monotonic tensile properties of $\mathrm{SiC} / \mathrm{SiC}$ minicomposites with BNNTs.

Table 3. Monotonic tensile properties of $\mathrm{SiC} / \mathrm{SiC}$ minicomposites without BNNTs.

Table 4. Ratio of different elements of SiC fiber with BNNTs. 
Table 1

\begin{tabular}{ccccc}
\hline Type of sample & Porosity & Density & Fiber volume content & Fiber orientation \\
\hline SiC/PyC/SiC & $\leq 10 \%$ & $\leq 2.5 \mathrm{~g} / \mathrm{cm}^{3}$ & $45 \%$ & Unidirectional \\
\hline SiC/PyC/BNNTs/SiC & $\leq 8 \%$ & $\leq 2.6 \mathrm{~g} / \mathrm{cm}^{3}$ & $45 \%$ & Unidirectional \\
\hline
\end{tabular}


Table 2

\begin{tabular}{cccc}
\hline Specimen & Elastic modulus/(GPa) & Tensile strength/(MPa) & Fracture strain/(\%) \\
\hline$\# 1$ & 71 & 262.8 & 0.374 \\
$\# 2$ & 70.2 & 258.3 & 0.366 \\
$\# 3$ & 71.5 & 253.5 & 0.383 \\
$\# 4$ & 83.5 & 268.1 & 0.366 \\
Average value & 74 & 260.6 & 0.372 \\
Standard deviation & 5.47 & 5.4 & 0.007 \\
\hline
\end{tabular}


Table 3

\begin{tabular}{cccc}
\hline Specimen & Elastic & Tensile & Fracture strain/(\%) \\
& modulus/(GPa) & strength/(MPa) & \\
\hline$\# 1$ & 90.2 & 485.6 & 0.658 \\
$\# 2$ & 92.4 & 502.6 & 0.683 \\
$\# 3$ & 95.9 & 482.9 & 0.642 \\
$\# 4$ & 92.1 & 507.8 & 0.648 \\
Average value & 92.6 & 494.7 & 0.657 \\
Standard deviation & 2 & 10.7 & 0.015 \\
\hline
\end{tabular}


Table 4

\begin{tabular}{cccccccc}
\hline Element & $\mathbf{B}$ & $\mathbf{N}$ & $\mathbf{S i}$ & $\mathbf{C}$ & $\mathbf{O}$ & $\mathbf{M g}$ & $\mathbf{F e}$ \\
\hline Weight \% & 39.1 & 30.5 & 12.5 & 11.5 & 5.3 & 0.6 & 0.5 \\
\hline
\end{tabular}




\section{Fig. captions}

Fig. 1. Schematic of fabrication of BNNTs using ball milling - annealing method.

Fig. 2. Schematic of tensile specimens of $\mathrm{SiC} / \mathrm{SiC}$ composites with and without BNNTs.

Fig. 3. Schematic of testing machine and tensile specimen.

Fig. 4. Monotonic tensile stress-strain curves of $\mathrm{SiC} / \mathrm{SiC}$ minicomposites (a) with BNNTs; and (b) without BNNTs.I

Fig. 5. Tensile stress-strain curve of $\mathrm{SiC} / \mathrm{SiC}$ minicomposite after heat-treatment at $1300{ }^{\circ} \mathrm{C}$.

Fig. 6. Cyclic compliance tensile curves of $\mathrm{SiC} / \mathrm{SiC}$ minicomposites (a) with BNNTs; and (b) without BNNTs.

Fig. 7. (a) Loading ITM; and (b) unloading ITM versus applied stress curves of $\mathrm{SiC} / \mathrm{SiC}$ minicomposite with BNNTs for different peak stresses of 75, 125, and $175 \mathrm{MPa}$.

Fig. 8. (a) Loading ITM; and (b) unloading ITM versus applied stress curves of $\mathrm{SiC} / \mathrm{SiC}$ minicomposite without BNNTs for different peak stresses of 150, 250, and $350 \mathrm{MPa}$.

Fig. 9. Microstructure observation on surface of SiC fibers with BNNTs under SEM

Fig. 10. Element analysis of SiC fiber with BNNTs

Fig. 11. Fracture morphology of $\mathrm{SiC} / \mathrm{SiC}$ minicomposite with BNNTs.

Fig. 12. Fracture morphology of $\mathrm{SiC} / \mathrm{SiC}$ minicomposite without BNNTs.

Fig. 13. Fracture morphology of $\mathrm{SiC} / \mathrm{SiC}$ minicomposite after heat-treatment at $1300{ }^{\circ} \mathrm{C}$.

Fig. 14. Experimental and predicted tensile stress-strain curves and broken fibers fraction versus applied strain curves of $\mathrm{SiC} / \mathrm{SiC}$ minicomposites with BNNTs.

Fig. 15. Experimental and predicted composite tangent modulus versus applied stress curves of SiC/SiC minicomposite with BNNTs.

Fig. 16. Experimental and predicted tensile stress-strain curves and broken fibers fraction versus applied strain curves of $\mathrm{SiC} / \mathrm{SiC}$ minicomposites without BNNTs. 
Fig. 17. Experimental and predicted composite tangent modulus versus applied stress curves of $\mathrm{SiC} / \mathrm{SiC}$ minicomposite without BNNTs. 
Figures

\section{precursor powder}

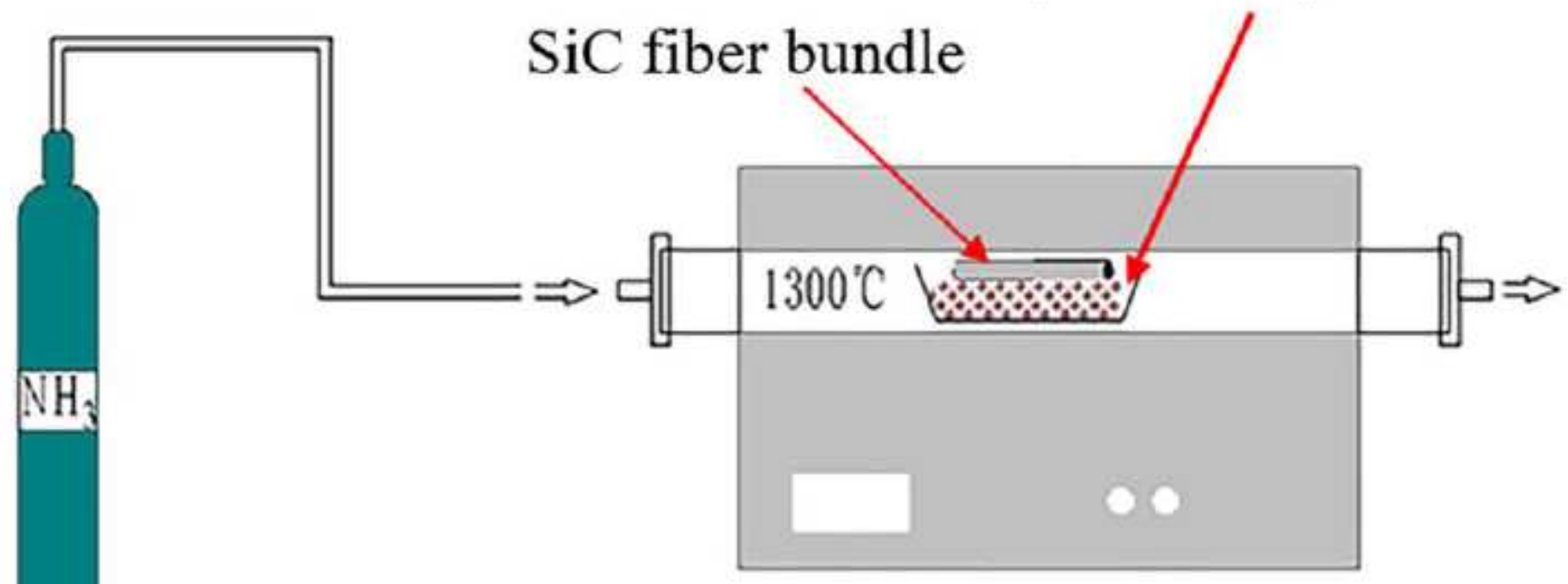

Figure 1

Sc he matic of fabrication of BNN Ts using ball mill ing anneal ing method.

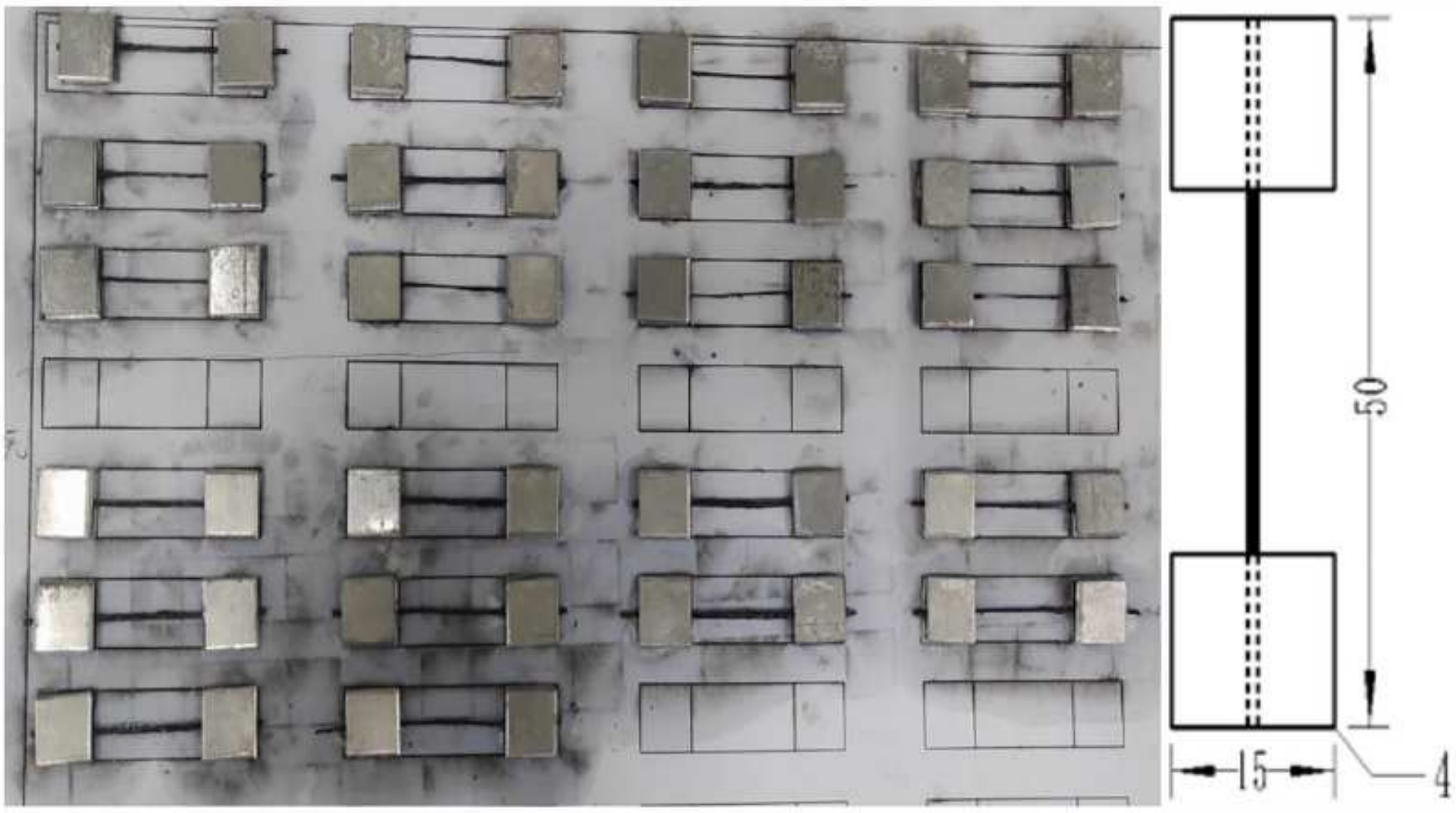


Figure 2

Schematic of tensi le sp e c imens of SiC/S iC co mposites with and without BNNTs.

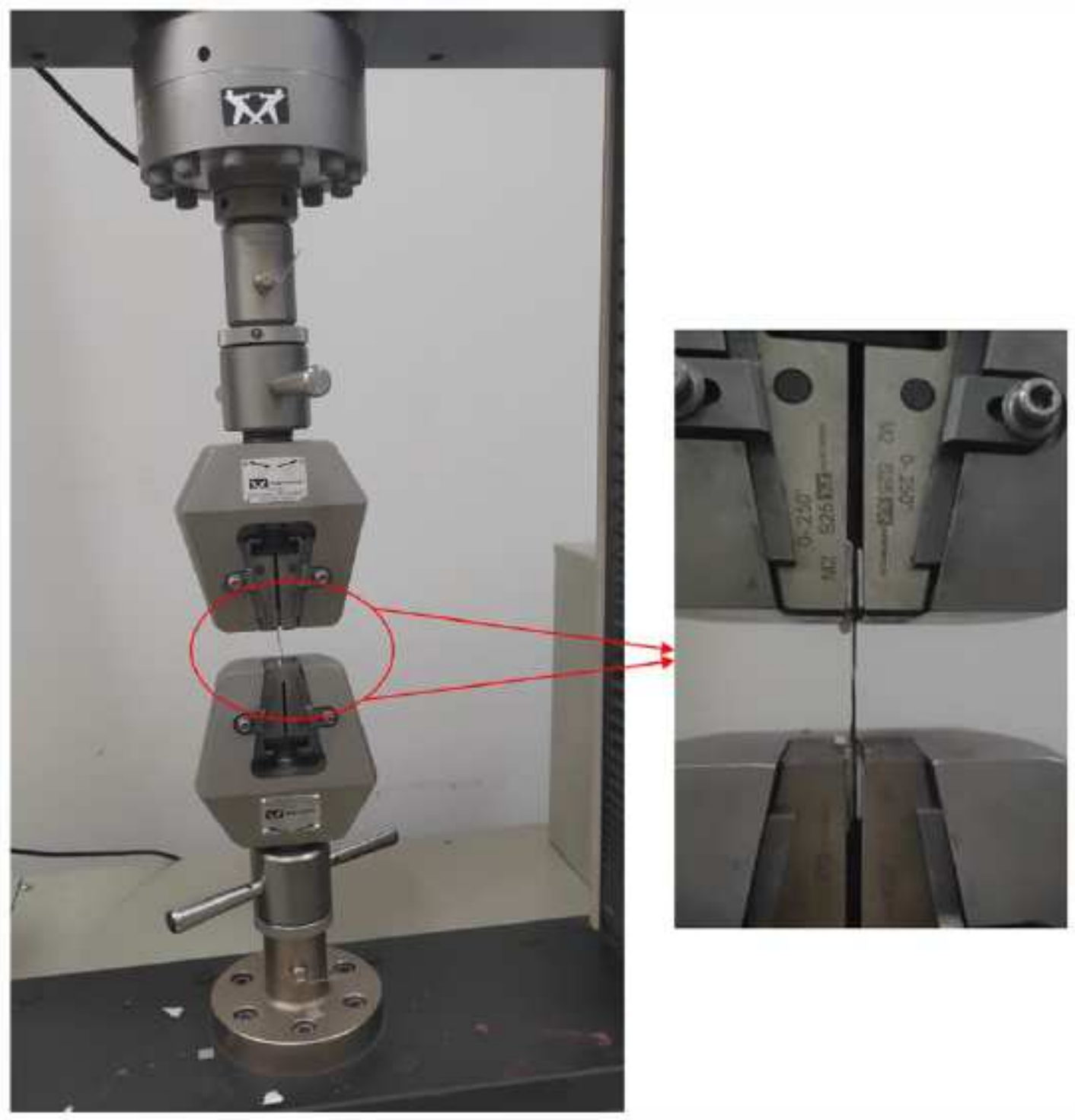

Figure 3

Schematic of testing machine and tensile speci men. 

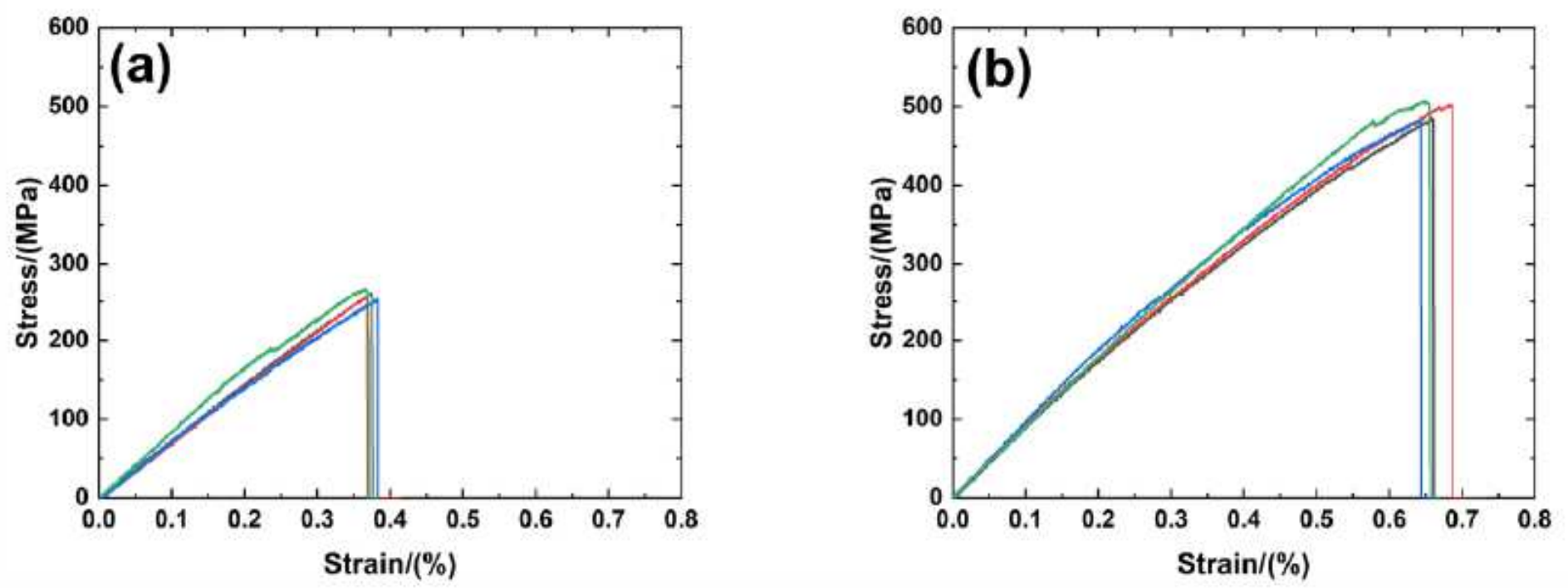

Figure 4

Monotonic tensile stress-strain curves of $\mathrm{SiC} / \mathrm{SiC}$ minicomposites (a) with BNNTs; and (b) without BNNTs.I

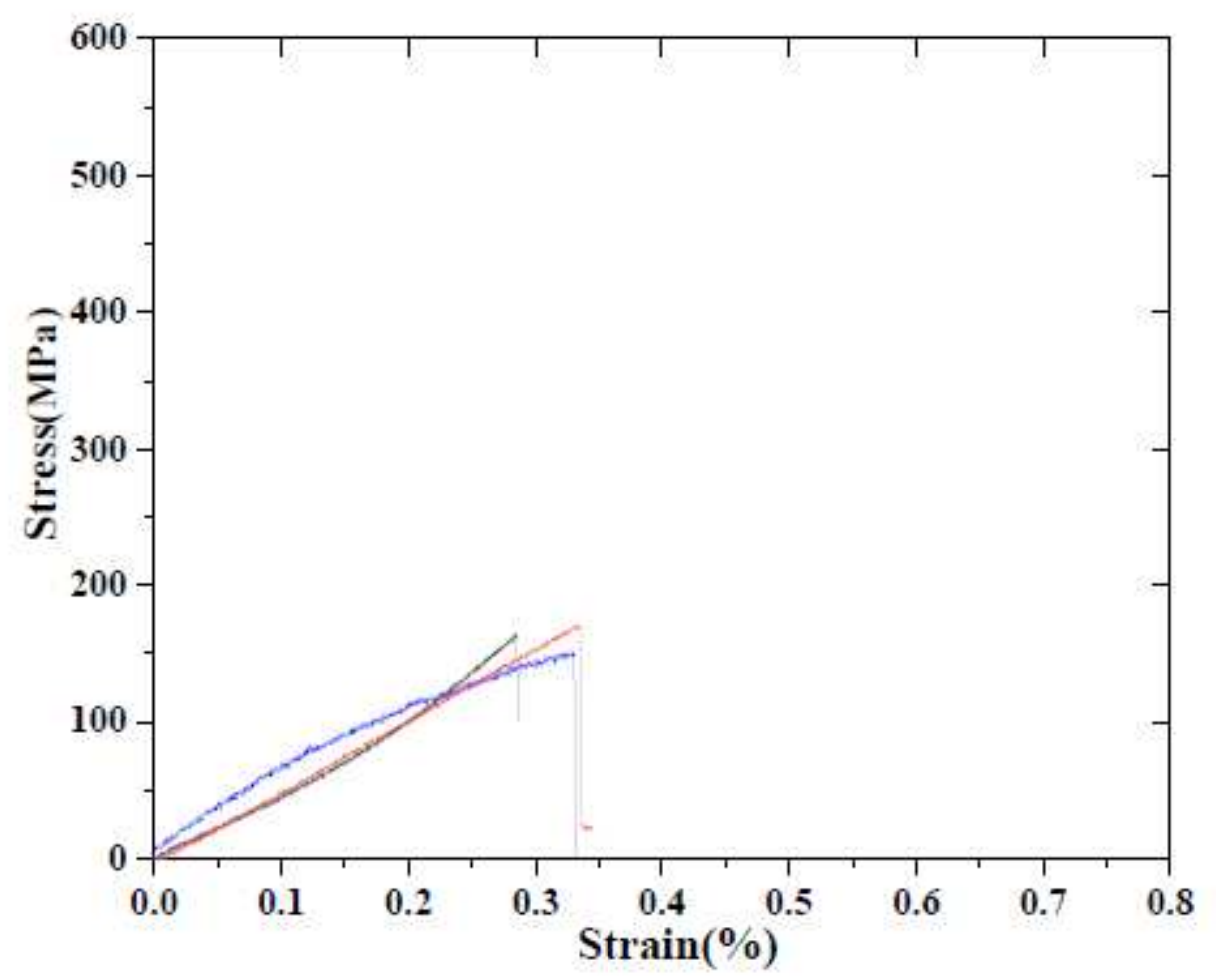

Figure 5

Tensile stress-strain curve of $\mathrm{SiC} / \mathrm{SiC}$ minicomposite after heat-treatment at $1300 \mathrm{oC}$. 

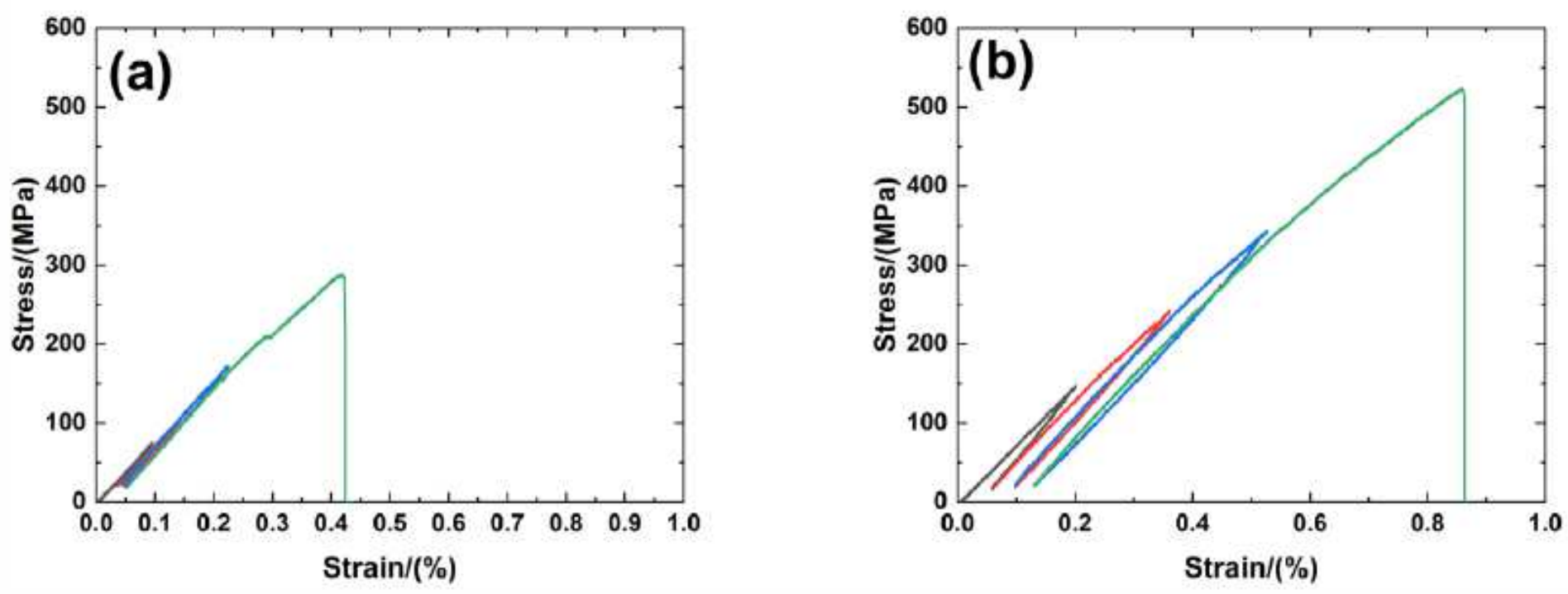

Figure 6

Cyclic compliance tensile curves of SiC/SiC minicomposites (a) with BNNTs; and (b) without BNNTs.
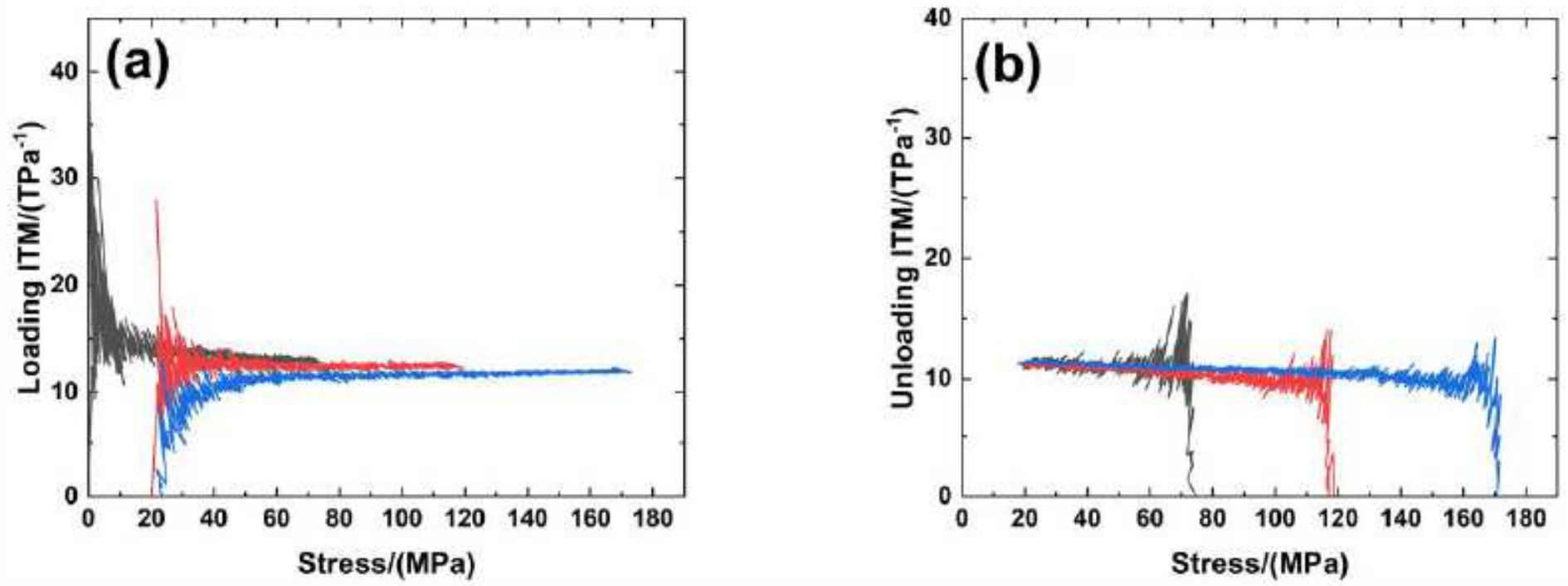

Figure 7

(a) Loading ITM; and (b) unloading ITM versus applied stress curves of $\mathrm{SiC} / \mathrm{SiC}$ minicomposite with BNNTs for different peak stresses of 75, 125, and $175 \mathrm{MPa}$. 

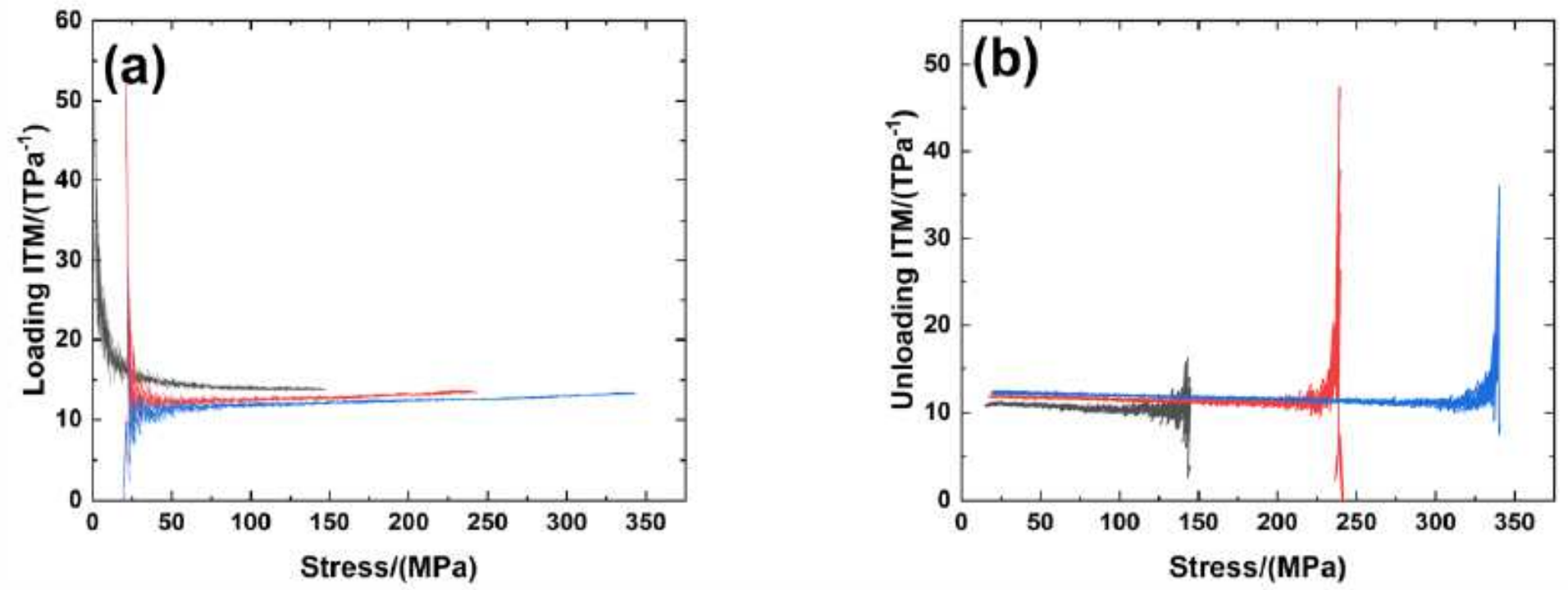

Figure 8

(a) Loading ITM; and (b) unloading ITM versus applied stress curves of SiC/SiC minicomposite without BNNTs for different peak stresses of 150, 250, and $350 \mathrm{MPa}$.

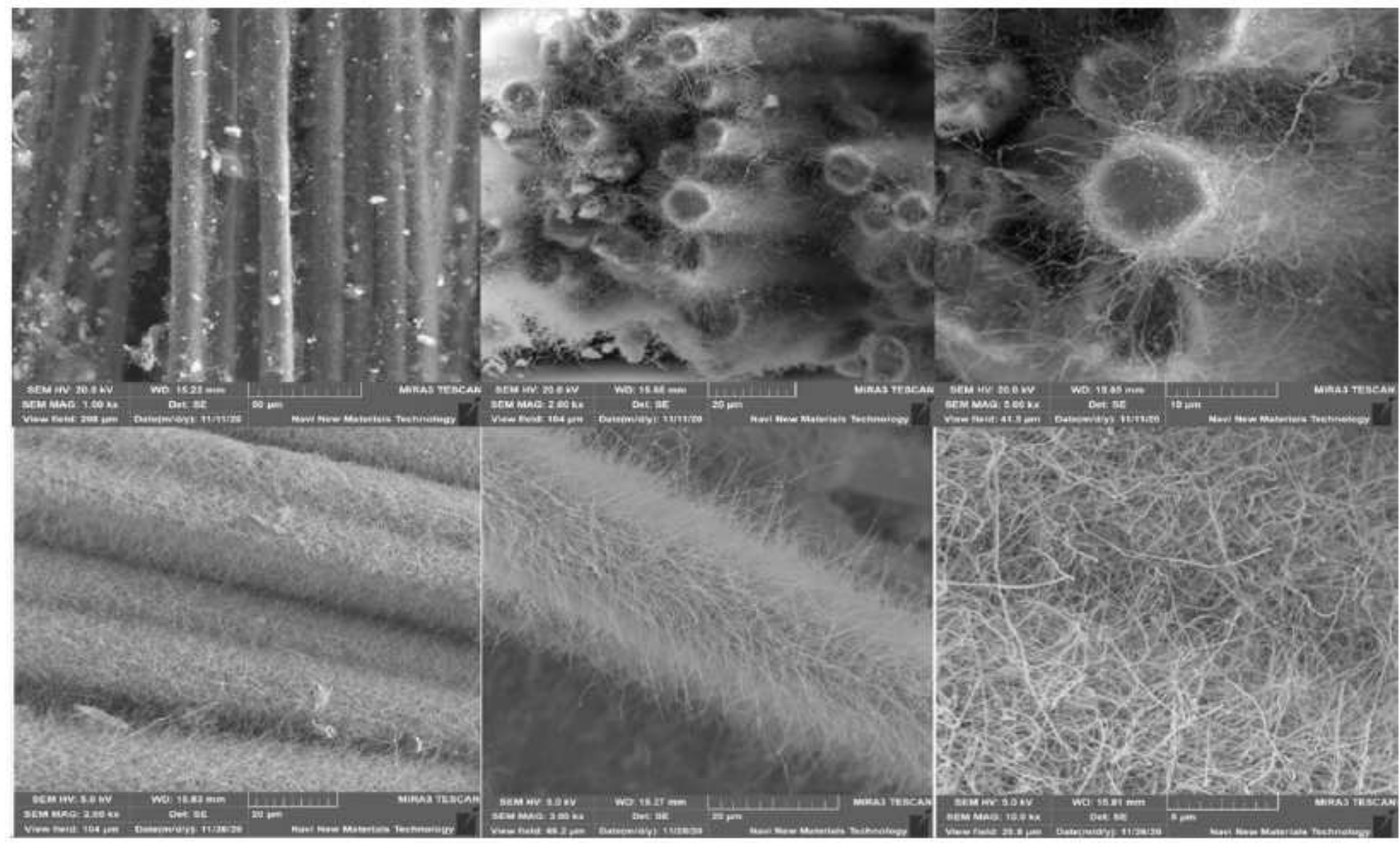

Figure 9

M icrostructure observation on surface of SiC fibers with BN NT s under SEM 
N Ka1_2

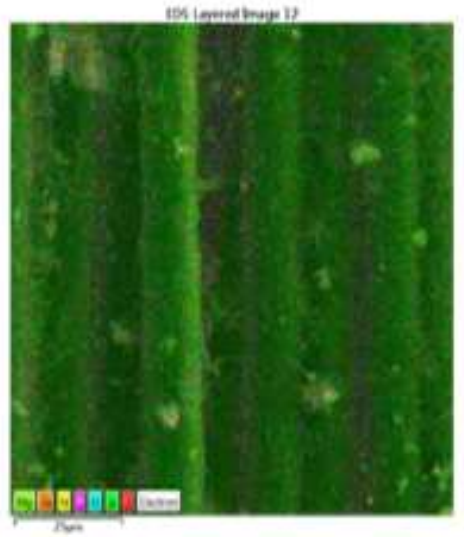

$\mathrm{C} K \alpha 12$

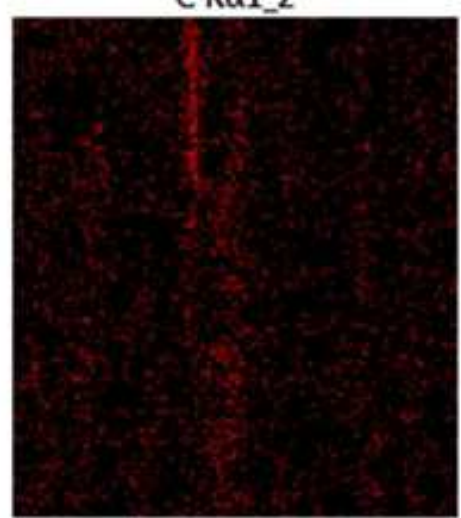

$\sqrt{25 \mu \mathrm{m}}$

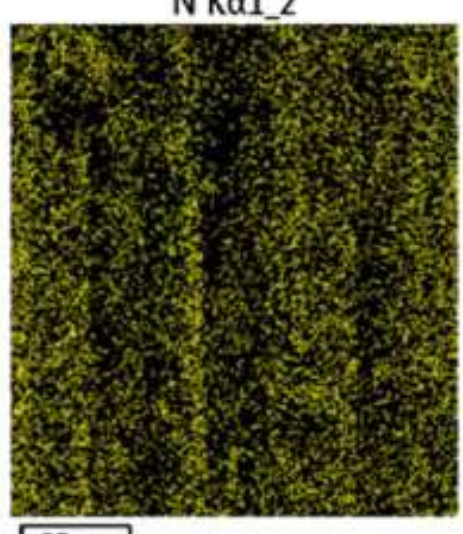

$\sqrt{25 \mu \mathrm{m}}$

$\mathrm{O} K \alpha 1$

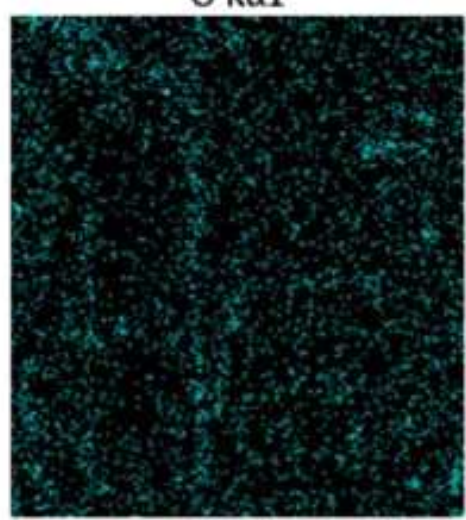

$\sqrt{25 \mu \mathrm{m}}$
B Ka1_2

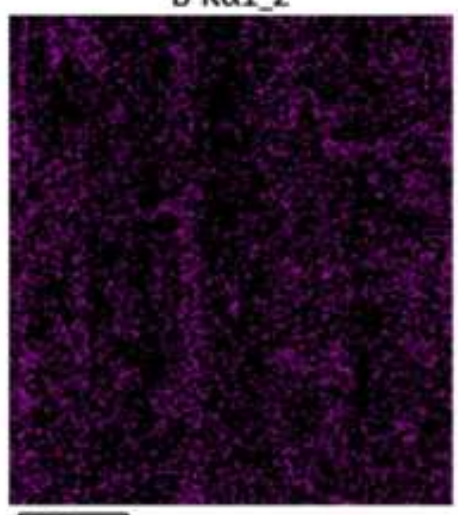

$\sqrt{25 \mu \mathrm{m}}$

$\mathrm{Mg} \mathrm{K \alpha 12}$

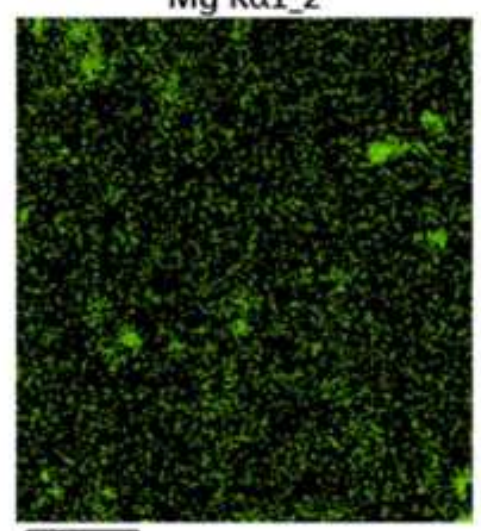

$\longdiv { 2 5 \mu \mathrm { m } }$
Si Ka1

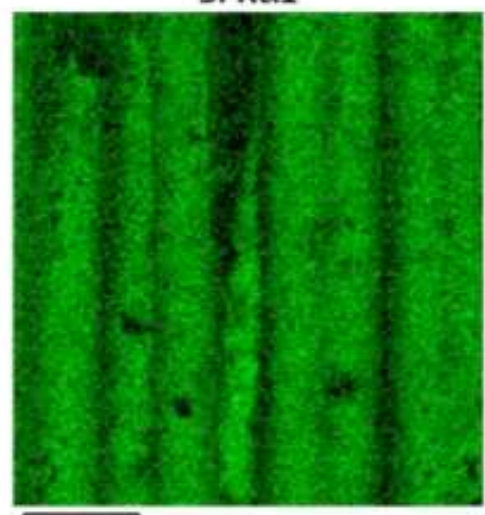

$\mathrm{Fe} \mathrm{K} \alpha 1$

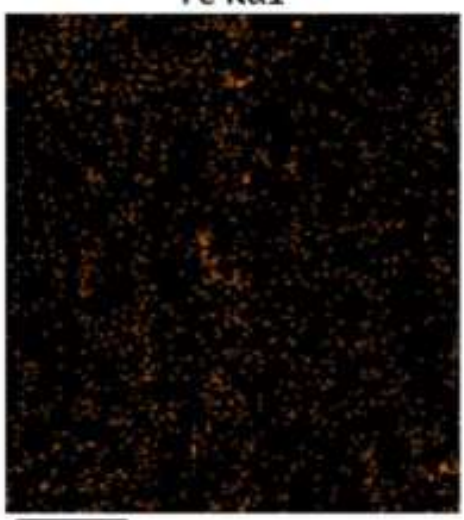

$\sqrt{25 \mu \mathrm{m}}$

Figure 10

Element analysis of S iC fiber with BNNTs 


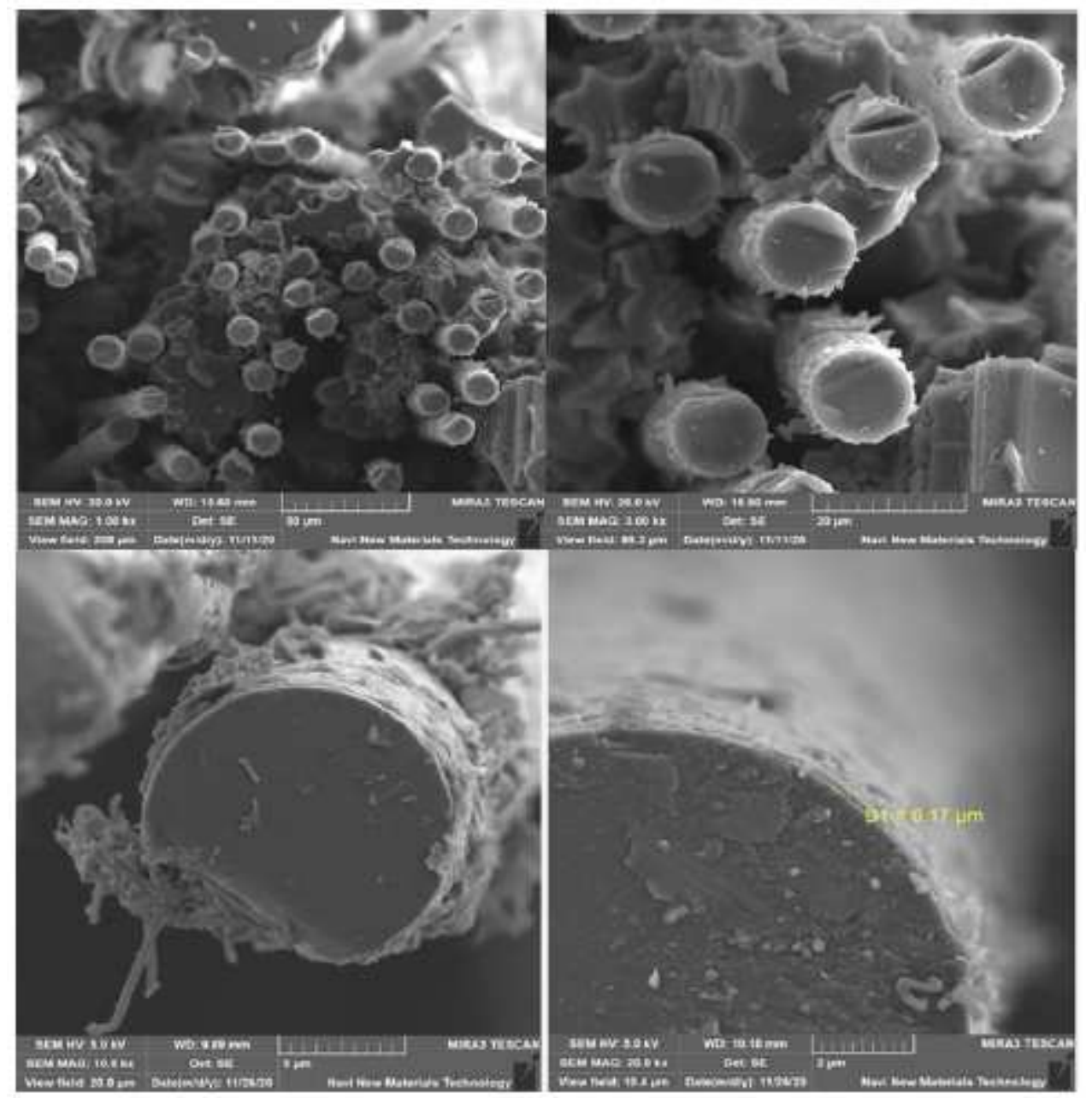

Figure 11

Fracture morphology of $\mathrm{SiC} / \mathrm{SiC}$ minicomposite with BNNTs. 


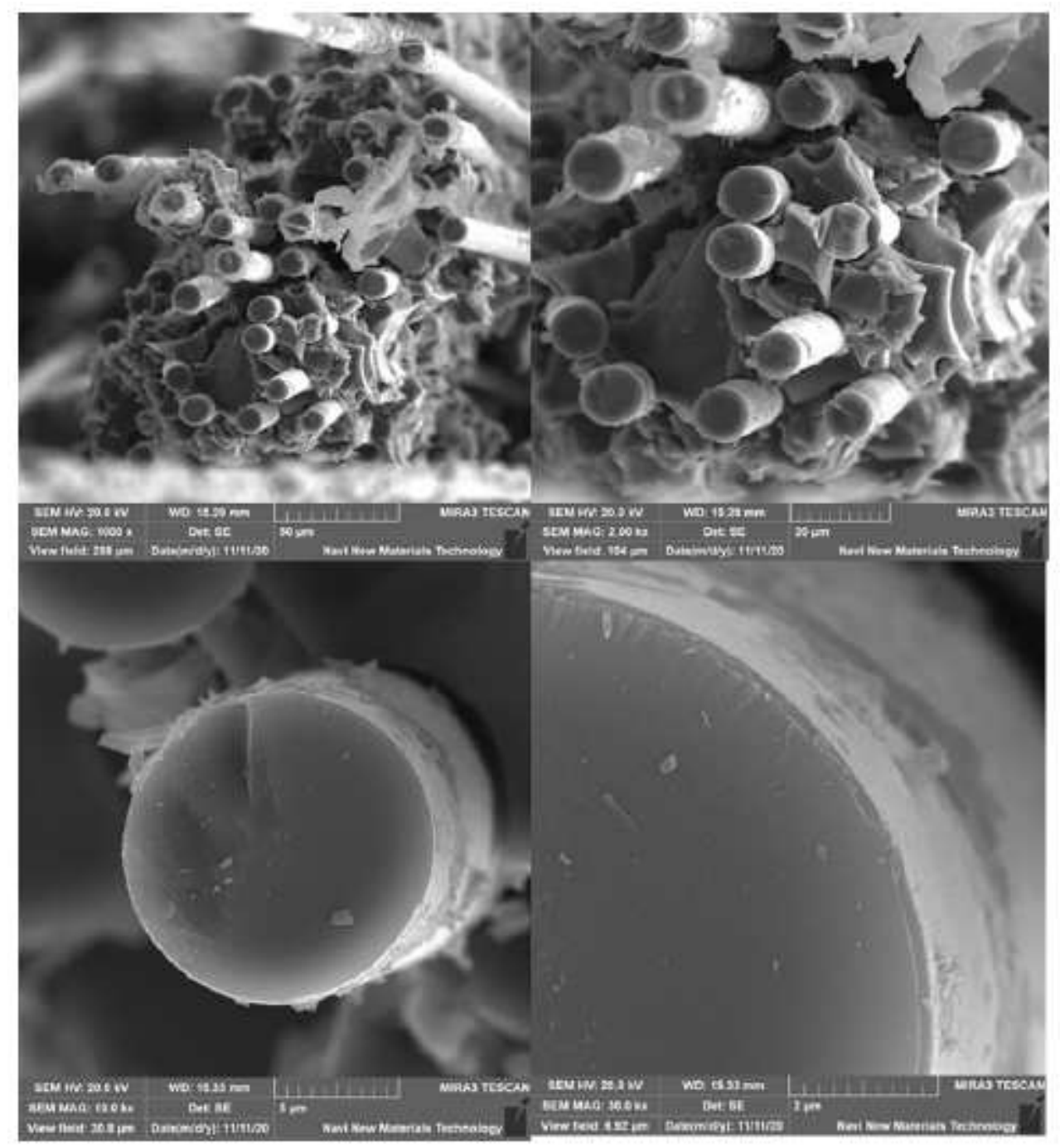

Figure 12

Fracture morphology of SiC/SiC minicomposite without BNNTs. 


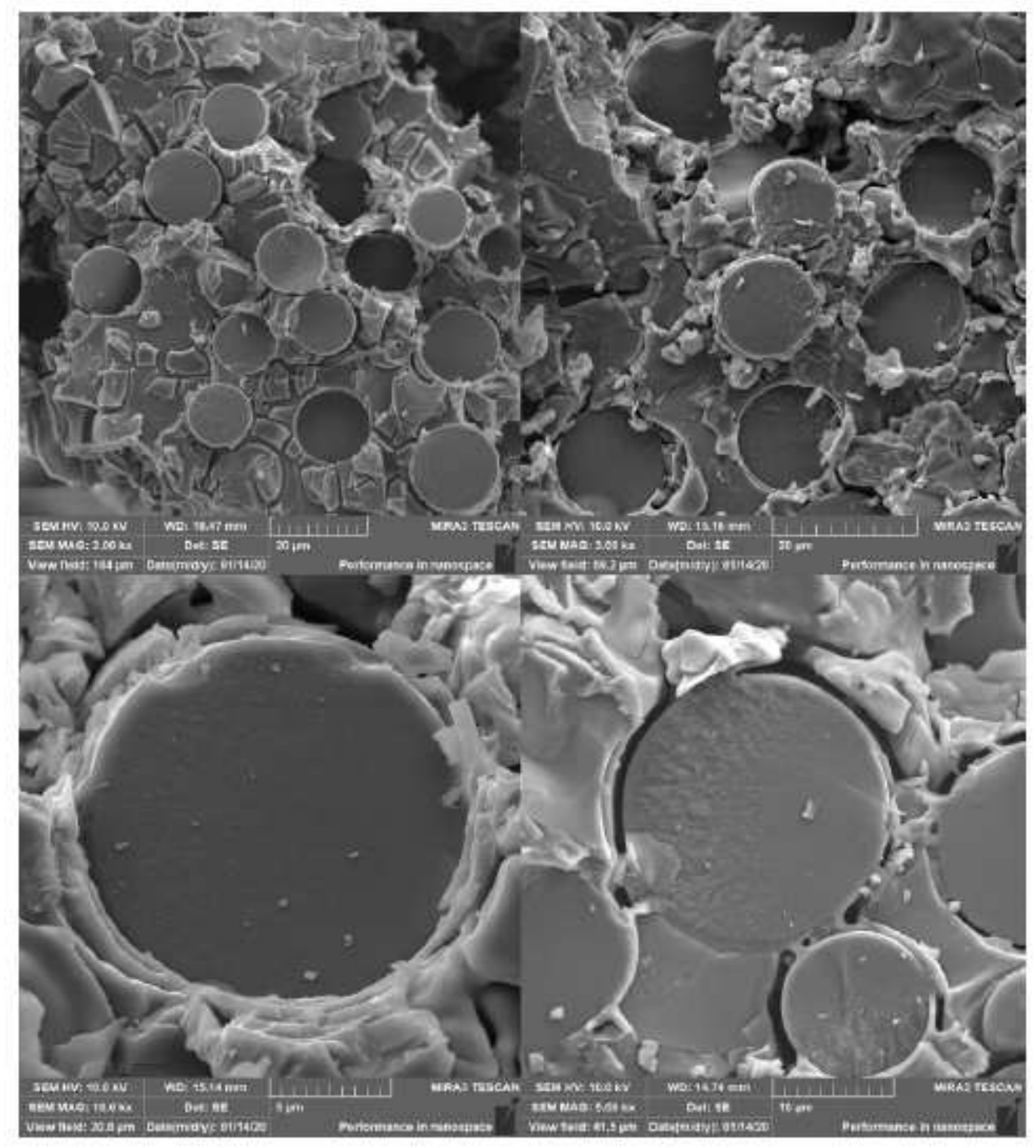

\section{Figure 13}

Fracture morphology of $\mathrm{SiC} / \mathrm{SiC}$ minicomposite after heat-treatment at $1300 \mathrm{oC}$. 


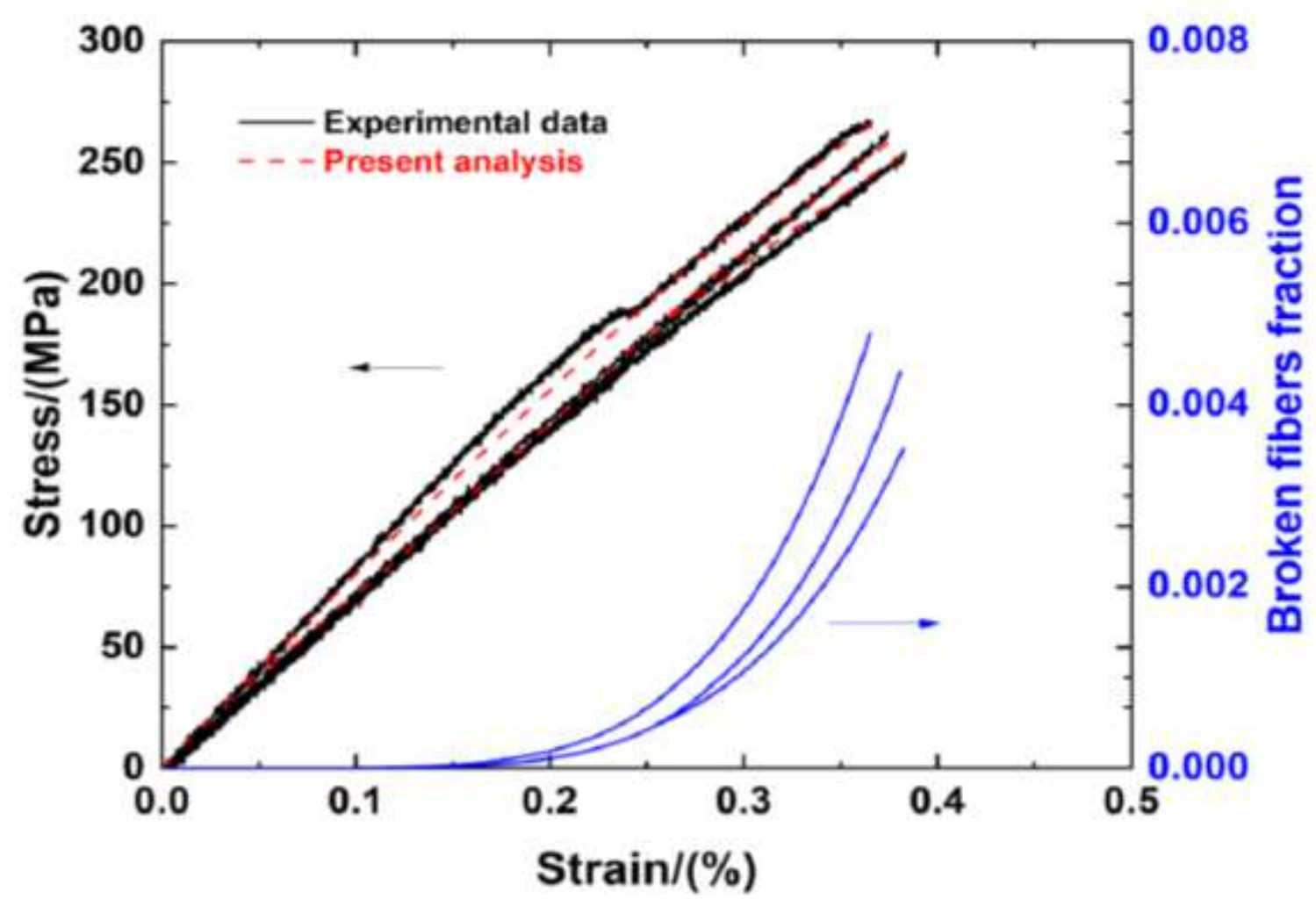

Figure 14

Experimental and predicted tensile stress-strain curves and broken fibers fraction versus applied strain curves of $\mathrm{SiC} / \mathrm{SiC}$ minicomposites with BNNTs. 

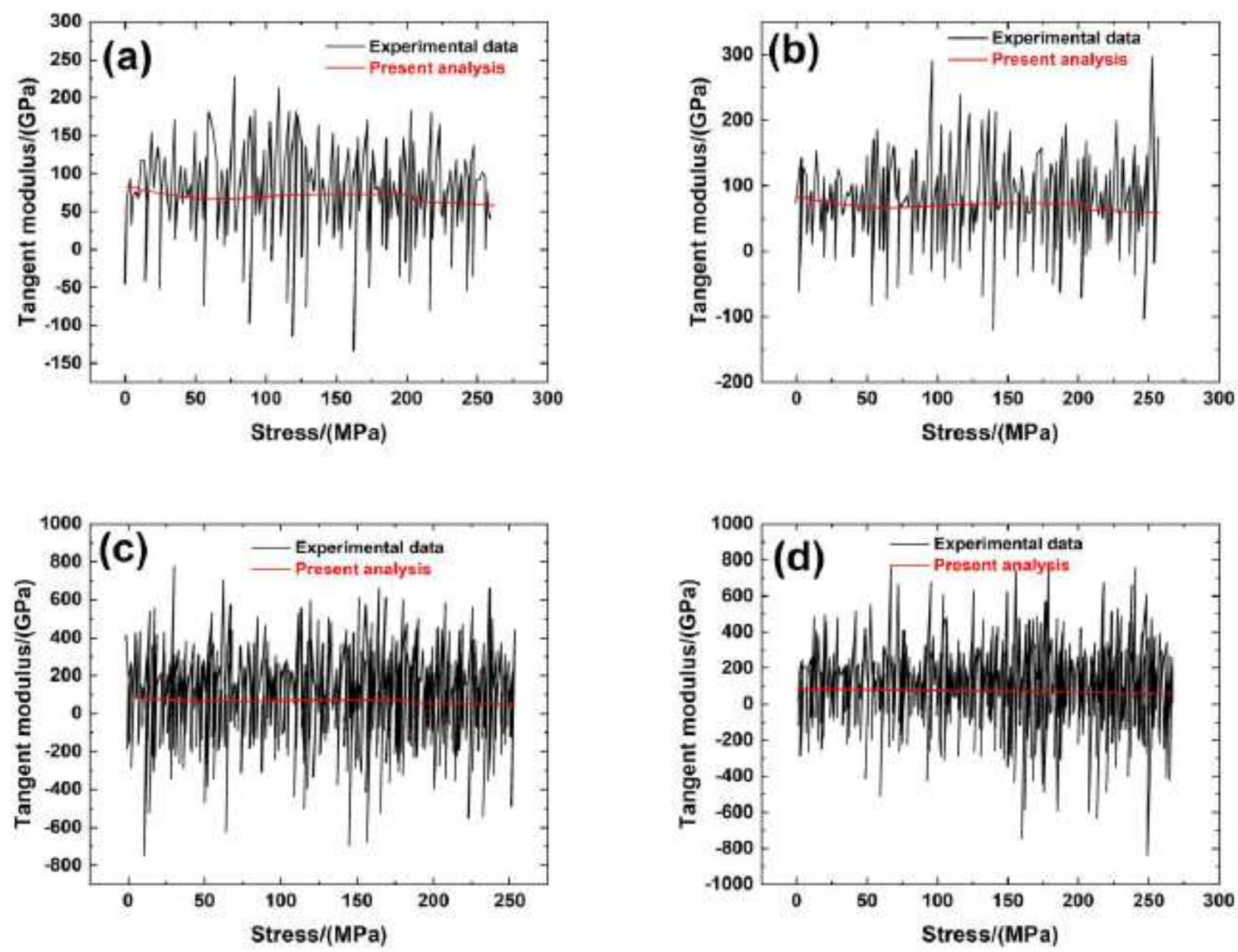

Figure 15

Experimental and predicted composite tangent modulus versus applied stress curves of $\mathrm{SiC} / \mathrm{SiC}$ minicomposite with BNNTs. 


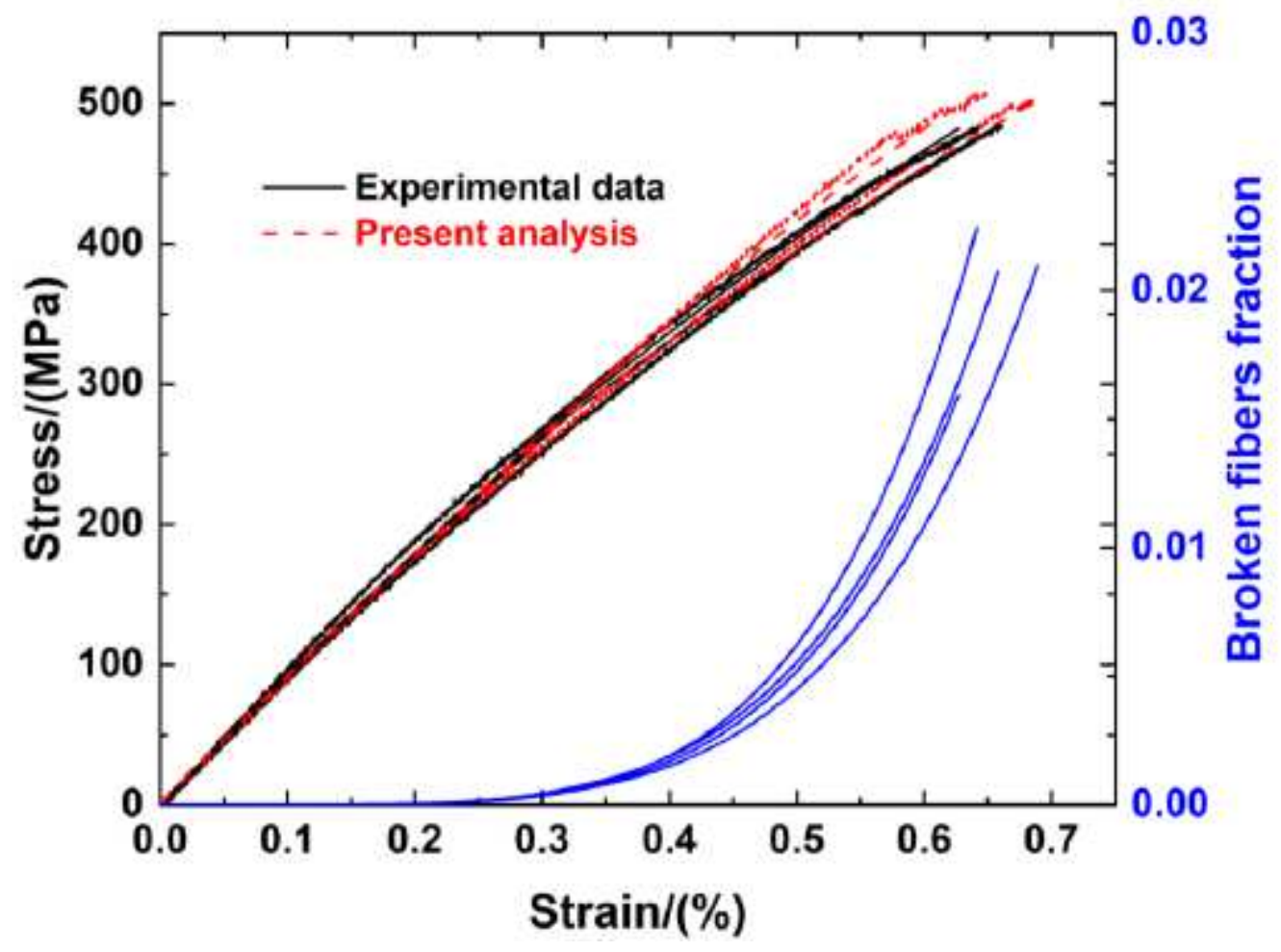

Figure 16

Experimental and predicted tensile stress-strain curves and broken fibers fraction versus applied strain curves of $\mathrm{SiC} / \mathrm{SiC}$ minicomposites without BNNTs. 

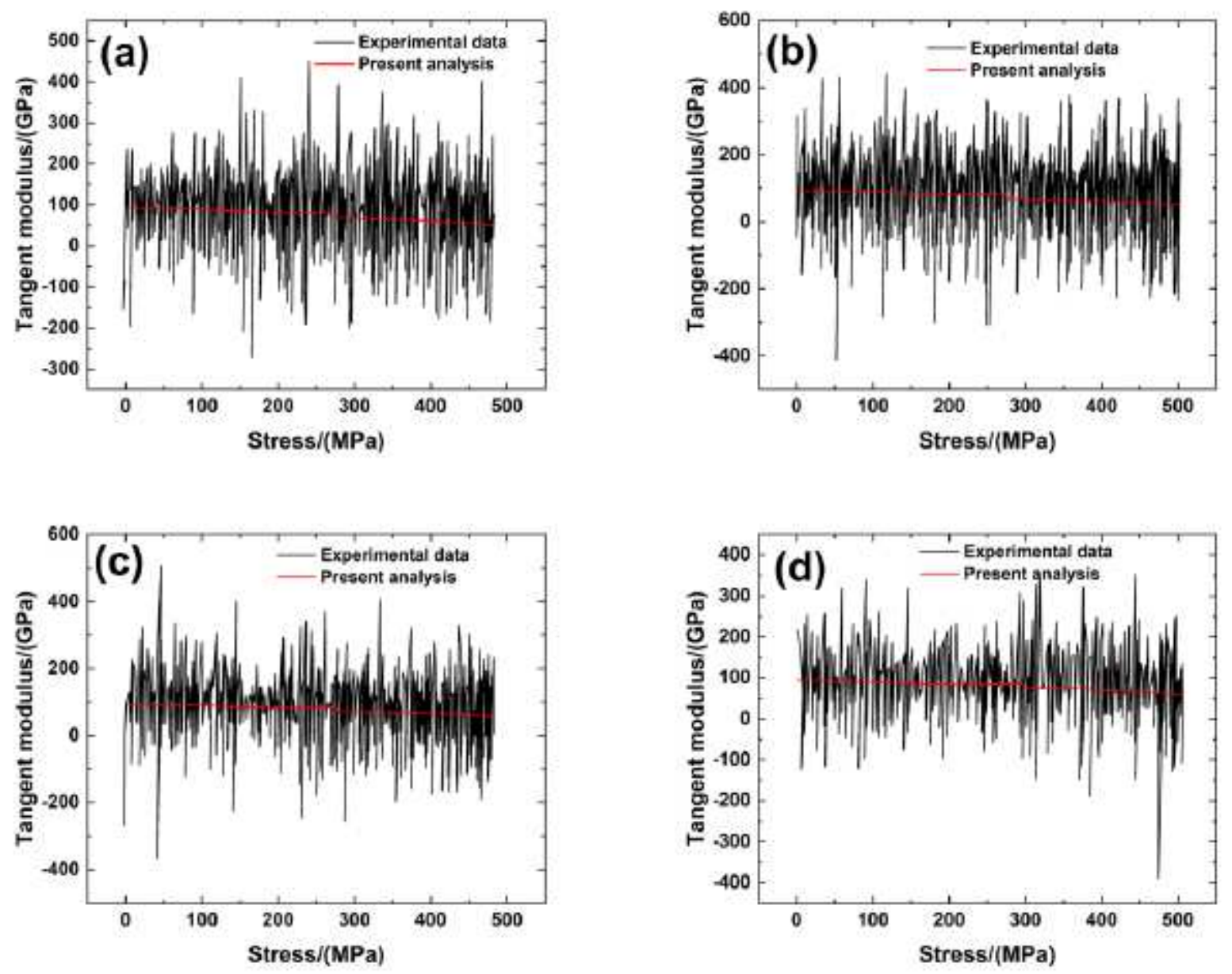

Figure 17

Experimental and predicted composite tangent modulus versus applied stress curves of $\mathrm{SiC} / \mathrm{SiC}$ minicomposite without BNNTs. 